\title{
Role of Dissolution AND Precipitation of Minerals in Controlling Soluble Aluminum in ACIDIC SoILS
}

\author{
G. S. P. Ritchie
}

\footnotetext{
I. Introduction

II. A Framework for Understanding Mineral Dissolution and Precipitation in Soils

III. Factors Affecting Dissolution and Precipitation of Aluminum-Containing Minerals

A. Solution Properties

B. Solid Properties

IV. Modeling Soluble Aluminum

A. Chemical Thermodynamic Approaches

B. Kinetic Approaches to Modeling

V. Aluminum in Acidic Soils: Principles and Practicalities

References
}

\section{INTRODUCTION}

Acidic soils are a worldwide phenomenon that may be natural or anthropogenic in origin. Acidic precipitation and farm management practices that disrupt the carbon, nitrogen, and sulfur cycles have apparently resulted in contemporary acidification rates that are much higher than rates estimated to occur in their absence (Binkley et al., 1989; Robson, 1989). Agricultural production on acidic soils may be severely limited by a number of nutritional (e.g., nitrogen or molybdenum deficiencies) or toxicity (e.g., aluminum or manganese) problems 
(Robson, 1989). Aluminum (Al) toxicity, however, is considered to be the most common cause of decreased plant growth in acidic soils.

The quantity of toxic $\mathrm{Al}$ in acidic soils has apparently defied prediction by chemical principles because the dynamic and diverse nature of soils distinguishes reality from ideality. The ultimate aim of soil scientists is to be able to predict Al speciation (solid and solution) in time and space and then deduce the quantity of $\mathrm{Al}$ that is toxic to plants.

There are several different forms of $\mathrm{Al}$ in soils (Adams, 1984; Ritchie, 1989; Sposito, 1989a) which can all contribute to the toxic quantity of Al in solution either directly or indirectly. Al-containing minerals are the ultimate source of $\mathrm{Al}$ in most soils whereas organically bound, exchangeable, interlayer, and soluble, complexed $\mathrm{Al}$ are sinks for $\mathrm{Al}^{3+}$ released during mineral dissolution. The sinks provide $\mathrm{Al}^{3+}$ to the soil solution in the short term and hence, separately or collectively, may be seen as controlling the amount of $\mathrm{Al}^{3+}$ in solution. In the long term, even though Al may be derived from mineral compounds, the quantity released cannot necessarily be predicted from equilibrium thermodynamics because morphological characteristics may result in the surface-free energy of the mechanism of structural breakdown being greater than the standard free energy of the reaction. When this occurs, kinetic considerations become more important than thermodynamics in controlling solution quantities of $\mathrm{Al}^{3+}$ (Morse and Casey, 1988).

Lewis and Randall (1923) pointed out that "thermodynamics shows us whether a certain reaction may proceed and what maximum yield may be obtained, but gives no information as to the time required." Hence our deductions about the processes controlling the dissolution and precipitation of $\mathrm{Al}$ will always be at the mercy of the time scale of our observations.

The processes and mechanisms of dissolution and precipitation have been under consideration by soil scientists and mineralogists for many years. In the context of Al solubility, an understanding of dissolution mechanisms and kinetics helps us see the limitations of trying to apply equilibrium thermodynamics to predicting activities in soil solutions and to decide on the most appropriate course of action for our needs.

The quantity of $\mathrm{Al}$ in the soil solution is dynamic in time and space and the measurements we make represent one moment in the time and space of a pathway. Soluble $\mathrm{Al}$ due to mineral dissolution and precipitation is the net result of the balance between thermodynamic and kinetic considerations, as affected by surface morphology, the uptake and release of nutrients and toxic ions by plants, and as affected by the composition and flow of water through the volume of soil being studied. When a mineral dissolves, whether it is a grain of feldspar in a granitic rock or kaolinite in a soil that is rewetting at the beginning of the wet season, the sequence of events that follows cannot be predicted by equilibrium 
thermodynamics alone. A process or sequence of events begins which can be described in terms of a pathway. The pathway is controlled by thermodynamics, kinetics, and surface morphology, which answer the questions: (1) what is it and where can it go? (thermodynamics), (2) how quickly will it get there? (kinetics), and (3) what does it look like? (surface morphology). For soil scientists and others working in the field, there is a fourth question: how do I know when it's there?

Many mechanisms have been put forward to describe dissolution but few have addressed all three scientific components influencing the process. Early work assumed the pathway was simply controlled by equilibrium thermodynamics (Garrels and Christ, 1965; Lindsay, 1979) but the inability of the theories to describe bulk solution concentrations led workers to postulate on nonequilibrium thermodynamics or on the physical structure of the dissolving surface and how they could lead to deviations from theoretical predictions based on the assumption of equilibrium (Helgeson, 1968; Hemingway, 1982; Hochella, 1990). In addition, the role of kinetics was also recognized to be so important (Morse and Casey, 1988) in some cases that it overshadows predictions from thermodynamic considerations.

All the theories and mechanisms that have been suggested to explain dissolution have one aspect in common: they cannot be proved unequivocally. Hypotheses that explain behavior in terms of surface morphology require experimental evidence on the molecular scale (Sposito, 1986). Until now most of the evidence has come from bulk solution measurements or spectroscopic analyses that are limited in their ability to distinguish between the surface and the interior of a mineral. However, recent advances in spectroscopic and microscopic techniques are providing methods that can study the hydrated surface layers of a dissolving grain (Hochella, 1990; Brown, 1990; Mogk, 1990).

This review considers the role of mineral dissolution and precipitation in controlling solution quantities of $\mathrm{Al}$ and our attempts to predict the outcome of these processes. Its purpose is to broaden our perspective and thereby increase our ability to predict $\left(\mathrm{Al}^{3+}\right)$ accurately by providing soil scientists with possibilities for looking at the problem from a different perspective by drawing on examples from related disciplines such as geochemistry. The dissolution and precipitation of $\mathrm{Al}$-containing minerals are by no means the only mechanisms controlling $\mathrm{Al}^{3+}$ in soil solutions (Ritchie, 1994). It is an area, however, that requires more clarity so that its contribution to the overall scheme of events can be appreciated more appropriately. The new perspectives may then enable us to predict more accurately the variation in solution composition with time and space of acidic or acidifying soils, before and after amelioration. Within this framework, the chemical paradigms that have been mistaken for principles and the paradigms of mineral and solution phases that exist in our soils in apparent defiance of chemical principles will be discussed. 


\section{A FRAMEWORK FOR UNDERSTANDING MINERAL DISSOLUTION AND PRECIPITATION IN SOILS}

In a closed system, the amount and composition of a mineral that dissolves or precipitates may be described in terms of chemical thermodynamics and kinetics as affected by the surface morphologies of the dissolving and precipitating species (Fig. 1). It is not possible to understand fully the processes and pathways of precipitation and dissolution without considering the interactions among thermodynamics, kinetics, and surface morphology.

Chemical thermodynamics describes the pathway and predicts mineral and solution speciation from the standard free energy change of a chemical reaction $\left(\Delta G_{\mathrm{r}}^{\circ}\right)$ and the composition of the soil solution and the minerals present. Such considerations may assume that equilibrium can be achieved [i.e., the free energy $(G)$ of the system reaches a minimum]; that non- or quasi-equilibrium exists [i.e., metastable products (e.g., smectites, Al-substituted goethite, and hematite) persist on a time scale considered long for soils]; or that an irreversible reaction occurs (i.e., a rock component dissolves completely).

Even though the driving force for precipitation or dissolution may be great from a thermodynamic standpoint (i.e., a lot of free energy, $\Delta G$, can be lost), the thermodynamic potential for a mineral to form or dissolve [(1) in Fig. 1] may be overshadowed by kinetic considerations. The rate of precipitation or dissolution

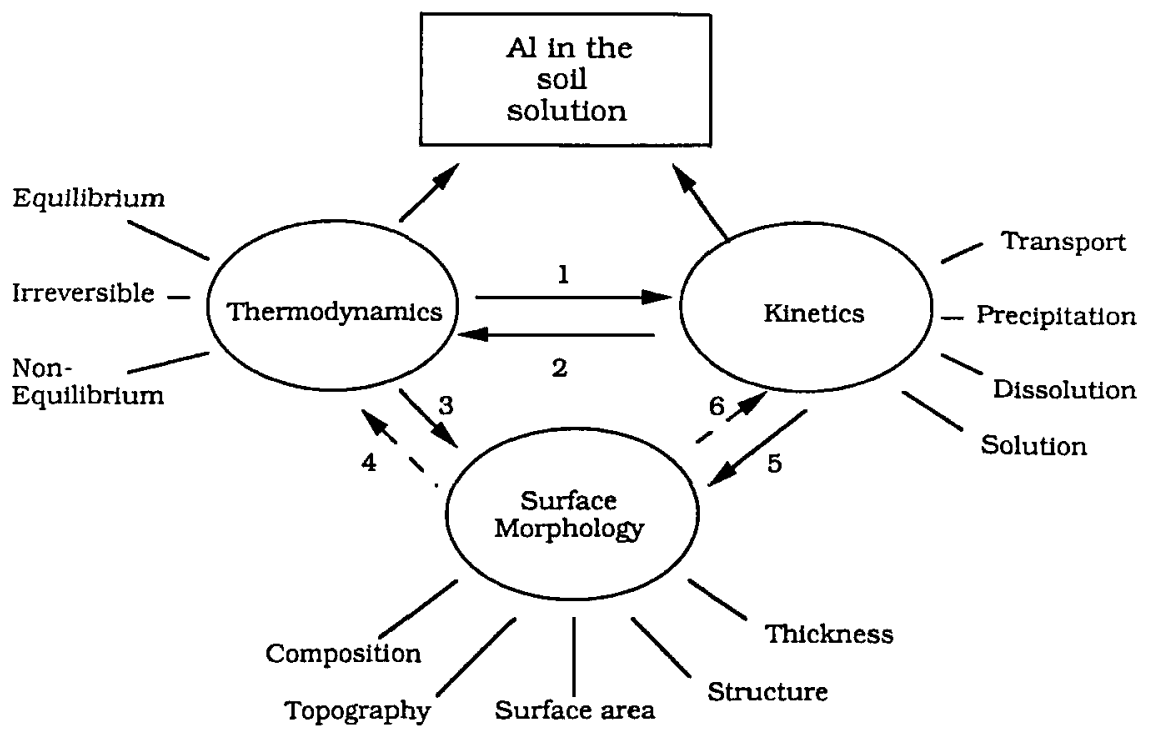

Figure 1 The three components influencing dissolution and precipitation. 
may be very small because the driving force (i.e., change in energy) is small. Thermodynamics indicates which reactions are possible whereas kinetics stipulate the time required for transformations and hence can frequently mediate the pathway of a reaction [(2) in Fig. 1]. Kinetic considerations include transport of ions in solution, reaction rates in solution, and rates of nucleation, crystal growth, and dissolution.

The energy changes described by chemical thermodynamics and kinetics during dissolution and precipitation may be modified by the surface morphology of the mineral (i.e., composition, structure, topography, thickness, and surface area). The surface morphology is the physical manifestation of the processes and rates of dissolution and precipitation. The soluble components predicted by thermodynamics can influence all the aspects of surface morphology [(3) in Fig. 1]. For example, nucleation and crystal growth could generate new species on a surface. Conversely, the processes of dissolution could modify the surface by producing leached layers or crystal ripening (Morse and Casey, 1988) could produce crystals of smaller surface area. In turn, surface morphology can affect the release or incorporation of solution components which change the free energy of solution and hence mineral reaction pathways may be altered [(4) in Fig. 1]. Kinetic factors can affect surface morphology [e.g., incongruent dissolution creates "leached layers" at a surface; (5) in Fig. 1] just as much as surface morphology will dictate the speed of dissolution and precipitation [(6) in Fig. 1].

\section{FACTORS AFFECTING DISSOLUTION AND PRECIPITATION OF ALUMINUM-CONTAINING MINERALS}

The surface and bulk properties of a mineral and the intensive and extensive properties of a solid-solution system can affect dissolution and precipitation by affecting each of the three components in the framework of Fig. 1 (Table I). Many of these factors are interrelated and hence the following discussion assumes all factors are constant other than the one being considered.

\section{A. Solution Properties}

The state of saturation of a solution plays a fundamental role in determining the reaction pathway and rate, and the surface mechanism controlling precipitation and dissolution (Van Straten et al., 1984; Nagy and Lasaga, 1992). The dissolution of a solid may be represented by the following type of reaction:

$$
\mathrm{Al}(\mathrm{OH})_{3(\mathrm{~S})} \rightleftharpoons \mathrm{Al}_{(\mathrm{aq})}^{3+}+3 \mathrm{OH}_{(\mathrm{aq})}^{-}
$$


Table I

System, Solution, and Solid-Phase Properties That Influence the Dissolution and Precipitation of Al Minerals ${ }^{a}$

\begin{tabular}{lll}
\hline \multicolumn{1}{c}{ System } & \multicolumn{1}{c}{ Solution } & \multicolumn{1}{c}{ Solid } \\
\hline 1. Temperature and pressure & 2. Saturation & 12. Bulk composition \\
& 3. $\mathrm{pH}$ & 13. Surface composition \\
4. $\mathrm{CO}_{2}$ & 14. Activity of solid \\
5. Activity of water & 15. Surface structure \\
6. Cations & 16. Surface transmissivity \\
7. Inorganic anions & 17. Surface thickness \\
8. Organic ligands & 18. Particle size \\
9. Ionic strength & 19. Particle surface area \\
10. pH buffering & 20. Particle surface tension \\
& 11. Polydispersity & 21. Precipitation of other minerals \\
\hline
\end{tabular}

$a$ The numbers are used to refer to this table in Tables II and VI.

The extent to which the reaction proceeds to the right-hand side of Eq. (1) depends on the solubility product constant, $K_{s p}$ :

$$
K_{s p}=\left(\mathrm{Al}^{3+}\right)(\mathrm{OH})^{3}
$$

where round brackets denote activities. The right-hand side of Eq. (2) is referred to as the ion activity product (IAP) and can be used to estimate the saturation of a solution with respect to a particular mineral by estimating the relative saturation (RS):

$$
\mathrm{RS}=\mathrm{IAP} / K_{s p}
$$

If $R S<1$, the solution is undersaturated; if $R S$ is $>1$, the solution is supersaturated. The logarithm of RS is sometimes referred to as the saturation index (SI).

The extent of saturation affects the reaction pathway of both dissolution and precipitation. Taking the dissolution of microcline in rainwater as an example, and assuming the very simple case that thermodynamic, partial equilibrium is possible (Tsuzuki, 1967), Fig. 2a shows that the reaction pathway depends on the initial $\mathrm{Al}$ saturation of the solution as the microcline begins to dissolve. As the microcline reacts with water it releases $\mathrm{Al}$ and $\mathrm{Si}$ into solution (A) at a rate that is sufficiently low for saturation to be $<1$ with respect to any $\mathrm{Al}-\mathrm{OH}$ or $\mathrm{Al}-\mathrm{Si}-\mathrm{OH}$ mineral. When the solution becomes saturated with respect to gibbsite $(\mathrm{B}), \mathrm{Al}$ will precipitate from solution while microcline continues to release $\mathrm{Al}$ and $\mathrm{Si}$. Eventually the $\mathrm{Si}$ activity will be high enough for kaolinite to precipitate (C) which will lower the $\mathrm{Al}$ activity below that controlled by gibbsite. Hence, gibbsite will start to dissolve and, even though microcline and kaolinite are both present, $\mathrm{Al}$ activity in solution will be controlled by gibbsite. During this stage, 

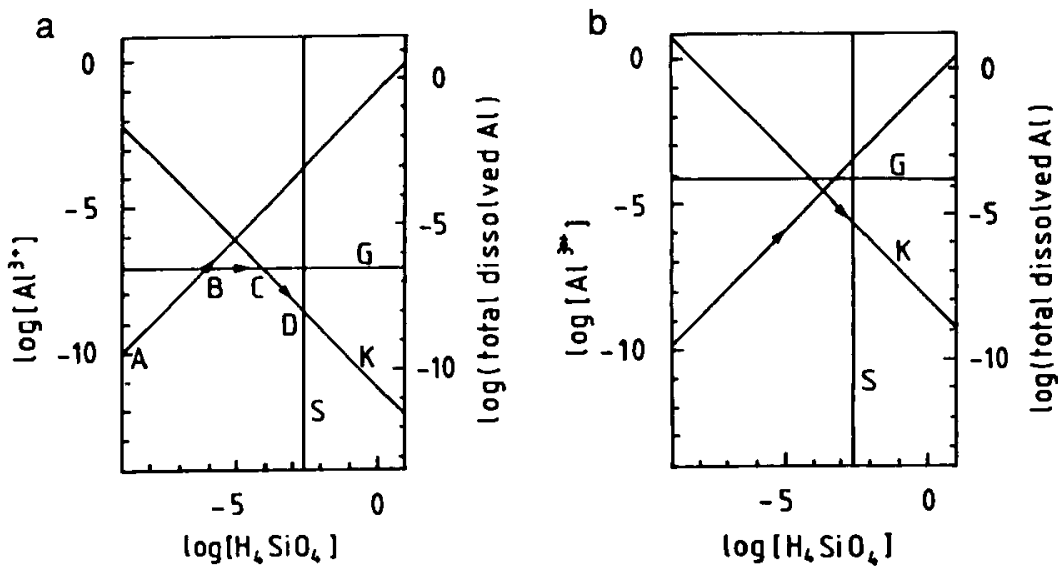

Figure 2 The variation in $\mathrm{Al}$ solubility at $\mathrm{pH} 5$ (a) and $\mathrm{pH} 4$ (b) during the weathering of microcline. The lines represent the ion activity product predicted from the $K_{s p}$ of minerals at equilibrium: G, gibbsite; K, kaolinite; S, amorphous silica. (After Tsuzuki, 1967.)

both gibbsite and microcline will be sources of $\mathrm{Al}$ for the kaolinite that precipitates. When all the gibbsite has dissolved, microcline continues to react to form kaolinite and the $\mathrm{Al}$ activity decreases whereas $\mathrm{Si}$ activity continues to increase until it is equivalent to that associated with amorphous silica at equilibrium. At this point, kaolinite and amorphous silica are in equilibrium (D). If the microcline dissolved more quickly in the initial reaction with rainwater, then the line $\mathrm{AB}$ would not be so steep and there would be less likelihood that gibbsite would form before kaolinite precipitated. This is the first example of how three mineral phases can be present but $\mathrm{Al}$ in solution is controlled by the least thermodynamically stable mineral. Even so, this is a very simplistic picture of what is happening and does not address the irreversibility of some of the reactions that occur (e.g., the precipitation of quartz).

The state of saturation also affects reaction kinetics. The rates of dissolution and precipitation slow down as equilibrium is approached. Hence, as water flows through a soil, the rate of dissolution in each successive volume of soil decreases because the flowing water contains an increasing amount of $\mathrm{Al}$ and is therefore nearer to equilibrium. This hypothesis is only relevant if other factors (such as $\mathrm{pH}$, soluble organic ligands) that affect dissolution rates do not vary significantly between successive volumes of soil. With respect to mechanisms acting in situations far from equilibrium (i.e., the magnitude of the driving force is large), the rate of dissolution is controlled by the soluble quantity of the mineral components and the presence of other ions that may inhibit or catalyze the dissolution process (Nagy and Lasaga, 1992). In the case of precipitation, the rate- 
controlling step may be diffusion to the surface because surface reactions could have become very rapid at high supersaturations (Zhang and Nancollas, 1990). Hence, the nucleation rates for all possible intermediary phases become very rapid and essentially similar. As the driving force for the reaction decreases, the total change in free energy for the reaction, $\Delta G_{\mathrm{r}}$ (this includes the Gibbs free energy change, $\Delta G_{\mathrm{r}}^{\circ}$ ) may also influence the rate of reaction and alter the ratecontrolling step. In addition, even if the variation in the rate of reaction with $\Delta G_{\mathrm{r}}$ has the same shape (e.g., linear) for both precipitation and dissolution in solutions near equilibrium, one cannot necessarily conclude that the same mechanism is controlling both reactions.

In the case of gibbsite at $\mathrm{pH} 3$ and $80^{\circ} \mathrm{C}$, Nagy and Lasaga (1992) found that the variation in dissolution rate with $\Delta G_{\mathrm{r}}$ could be explained most easily by postulating that dissolution occurs at dislocation screw defects on basal surfaces at saturations near equilibrium. In solution far from equilibrium, however, the dissolution rate was much greater and was consistent with the formation of etch pits. It was also possible that the functional dependence of rate on $\Delta G_{\mathrm{r}}$ was due to changes in solution or surface speciation of $\mathrm{Al}$ with the extent of solution saturation.

$\mathrm{pH}$ affects dissolution and precipitation because it takes part in the reaction, it acts as a catalyst, or it changes the reaction pathway or surface morphology. Lowering the $\mathrm{pH}$ (as in an acidifying soil) can change the reaction pathway by changing the extent of saturation (Tsuzuki, 1967). Figure 2 indicates that as the $\mathrm{pH}$ falls from 5.0 to 4.0 the reaction pathway of dissolution of microcline changes from:

$$
\begin{aligned}
& \text { microcline } \rightarrow \text { gibbsite } \rightarrow \text { kaolinite } \rightarrow \text { kaolinite }+ \text { amorphous silica } \\
& \text { to }
\end{aligned}
$$

microcline $\rightarrow$ kaolinite $\rightarrow$ kaolinite + amorphous silica

Specific adsorption of $\mathrm{H}^{+}$and $\mathrm{OH}^{-}$can alter the surface charge of a mineral and hence decrease the rate of nucleation by lowering the interfacial tension (Van Straten et al., 1984). Stumm and co-workers (Stumm and Wieland, 1990, and references therein) consider adsorption to consist of several stages of which the detachment of an activated surface complex is the rate-limiting step and hence controls the dissolution rate (Fig. 3). They found that the rate of dissolution of metal oxides was proportional to the surface concentration of $\mathrm{H}^{+}$ions raised to the power equivalent to the charge of the metal cation (Fig. 4). Understanding the effect of $\mathrm{pH}$ on the dissolution rate of $\mathrm{Al}$ from layer silicates is not as straightforward because of the presence of $\mathrm{pH}$-independent sites. In general, it appears that $\mathrm{Al}$ dissolution from kaolinite, anorthite, and montmorillonite is independent of $\mathrm{H}^{+}$concentration in the $\mathrm{pH}$ region $\sim 4-9$ whereas at $\mathrm{pH}<4$, Al dissolution rates can be explained by the metal oxide model (Amhrein and Suarez, 1988; Wieland and Stumm, 1992; Furrer et al., 1993). 

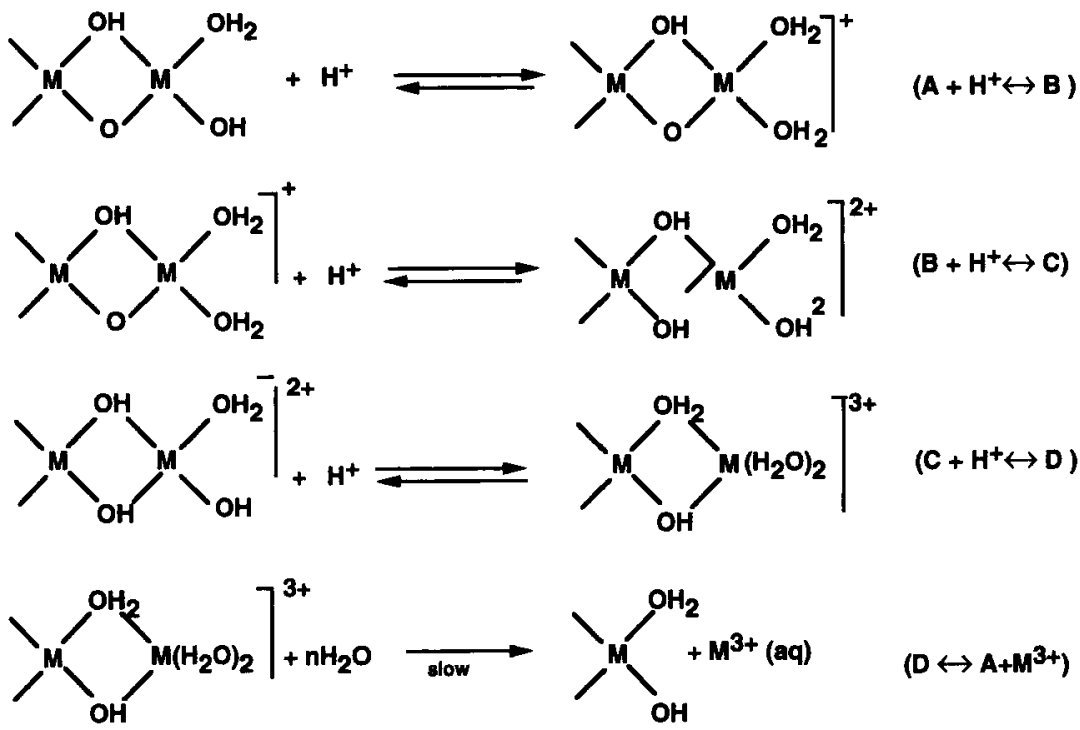

Figure 3 Schematic representation of proton-promoted dissolution of a metal oxide, $\mathrm{M}_{2} \mathrm{O}_{3}$. (After Stumm and Wieland, 1990, in "Aquatic Chemical Kinetics," copyright (C) 1990, by permission of John Wiley and Sons, Inc.)

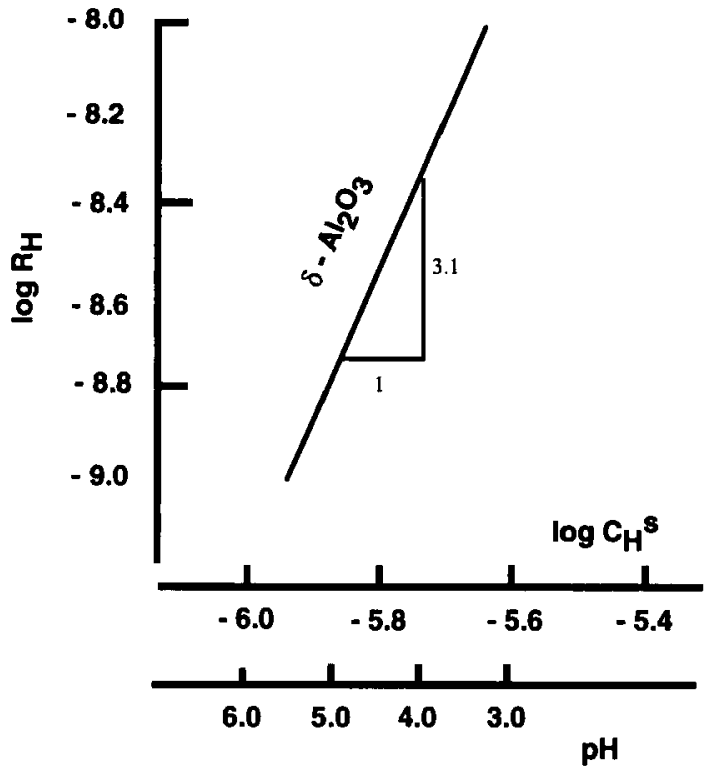

Figure 4 The relationship between the rate of proton-promoted dissolution $\left(R_{H}, \mathrm{~mol} \mathrm{~m}^{-2} \mathrm{sec}^{-1}\right)$ and $\mathrm{pH}$ or the concentration of protonated surface hydroxyls, $\mathrm{C}_{\mathrm{H}^{\mathrm{s}}}$, in mol $\mathrm{m}^{-2}$. (After Stumm and Wieland, 1990, in "Aquatic Chemical Kinetics," copyright (C) 1990, by permission of John Wiley and Sons, Inc.) 
In soils, the effect of $\mathrm{pH}$ on dissolution may be confounded by precipitation or adsorption of $\mathrm{Al}$ on the mineral surface at pH 4-5 (Wieland and Stumm, 1992; Furrer et al., 1993). This mechanism appears to block dissolution sites and hence decreases the rate of dissolution of Al.

Increasing the $\mathrm{pH}$ to very high values ( $\mathrm{pH}>12$; as may occur temporarily in soil around a dissolving grain of lime) dehydrates $\mathrm{Al}(\mathrm{OH})_{3}$ linkages to $\mathrm{AlO}_{2}-$ and changes the reaction pathway to favor the precipitation of fine-grained, poorly crystalline boehmite (referred to as pseudo-boehmite) rather than bayerite (Hemingway, 1982). As mixing of $\mathrm{OH}^{-}$with the soil increases with time, the localized ratio of $\mathrm{OH}$ and $\mathrm{Al}$ will decrease until dehydration is no longer favored. At this stage, the pseudo-boehmite will stop precipitating and an $\mathrm{Al}(\mathrm{OH})_{3}$ solid phase will form. The pseudo-boehmite will then dissolve in response to the removal of $\mathrm{Al}$ from solution as $\mathrm{Al}(\mathrm{OH})_{3}$ precipitates.

Exchange of $\mathrm{H}^{+}$for $\mathrm{Al}^{3+}$ in the surface layers of a dissolving mineral will change the surface morphology and temporarily affect the dissolution rate (Casey and Bunker, 1990).

Ionic strength (I) affects dissolution and precipitation by changing the activity of soluble mineral components, the relative amounts of the species of each component and by changing the surface concentration of $\mathrm{H} / \mathrm{OH}$ ions. Increasing ionic strength decreases the activity of $\mathrm{Al}^{3+}$ and hence more $\mathrm{Al}^{3+}$ is released by the mineral dissolving in an attempt to restore the original equilibrium. This is balanced partially by a simultaneous increase in the ratio of $\mathrm{Al}^{3+}$ and monomeric hydroxy species. Such changes can affect the reaction rate and pathways and the surface morphology. Accordingly, Furrer et al. (1991) found that the dissolution rate of montmorillonite was approximately doubled when the ionic strength was raised from 0.1 to $1 M$.

The presence of cations and anions other than those forming the minerals under consideration can change the speciation of soluble mineral components and hence the reaction pathways. They can also affect reaction rates and surface morphology by being specifically adsorbed, incorporated as an impurity, coprecipitating, or by precipitating on a mineral surface.

Inclusion (as defined in Sposito, 1989b) lowers the activity of the solid and produces a strain on the crystal structure, both of which decrease solubility (Sposito, 1984). Precipitation of a new phase on a mineral will change the surface area and tension and may block sites for nucleation or dissolution, or hinder crystal growth.

The presence of anions can alter the reaction pathway and rate by inhibiting or promoting polymerization and precipitation, forming new compounds or solid solutions with the components of pre-existing minerals, and by retarding crystallization (Zawacki et al., 1986; Hemingway, 1982; Bertsch, 1989; Davis and Hem, 1989). For example, specific adsorption onto variable charge surfaces of anions that form bidentate mononuclear surface complexes (e.g., oxalate, salicylate, citrate) will enhance short term $(<50 \mathrm{hr})$ dissolution (Fig. 5), whereas 


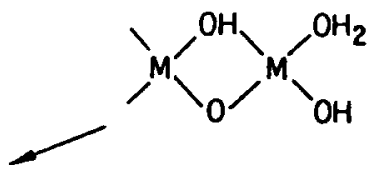

Enhancement of dissolution

Inhibition of dissolution
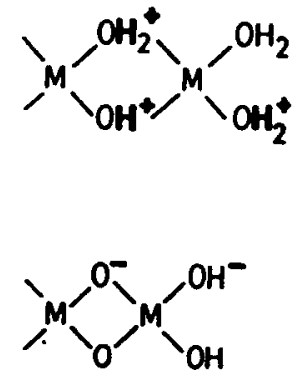

Surface protonation

Surface deprotonation<smiles>CC(C)O[Al]1CCCO1</smiles>

Surface complex formation with ligands that form bidentate. mononuclear surface complexes, e.g., oxalale, salicylate, citrate, diphenols, etc.

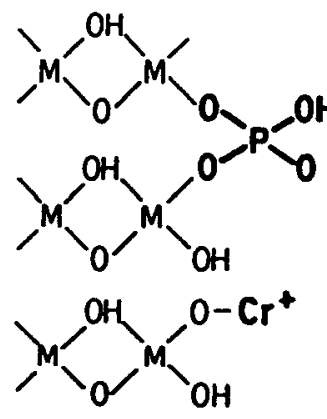

Surlace complex. lormation to bi-/or multinuclear com plexes or surface lilms: blockage of surlace groups by metal cations<smiles>CC(C)O[W](O)(O)O[V]</smiles>

$\mathrm{CH}_{3} \sim\left(\mathrm{CH}_{2}\right)-\mathrm{COOH}$ $\mathrm{CH}_{3} \sim\left(\mathrm{CH}_{2}\right)_{n}-\mathrm{COOH}$<smiles>CC(C)O[Al](O)(O)O[Na]</smiles><smiles></smiles>

Blocking ol surface groups by hydrophobic moieties of fatty acids, humic acids or macromolecules Figure 5 The enhancement and inhibition of dissolution by the adsorption of cations and anions. (After Hering and Stumm, 1990, copyright by the
Mineralogical Society of America.) 
specific adsorption of ligands that form multinuclear surface complexes or block surface reactive groups retard short-term dissolution (Fig. 5) (Stumm and Wieland, 1990). The extent to which an organic ligand increases the short-term dissolution rate of $\alpha-\mathrm{Al}_{2} \mathrm{O}_{3}$ correlates with the ability of an anion (within a given structural class) to complex $\mathrm{Al}^{3+}$ in solution (Furrer and Stumm, 1986). In contrast, the presence of organic ligands does not significantly enhance the longterm dissolution of corundum (Carroll-Webb and Walther, 1988). The results for layer silicates are also inconclusive. The long-term dissolution of anorthite increases in the presence of oxalate at pH 4.2-9 (Amhrein and Suarez, 1988) whereas organic ligands do not affect kaolinite dissolution (Carroll-Webb and Walther, 1988).

The presence of ligands that form soluble complexes with $\mathrm{Al}$ can prevent the formation or rapid polymerization of hydroxy-Al at $\mathrm{pH}<6.5$ which can favor the formation of $\mathrm{Al}-\mathrm{O}-\mathrm{Si}$ or $\mathrm{Al}$-ligand bonds. Therefore, kaolinite may be more prevalent than $\mathrm{Al}(\mathrm{OH})_{3}$ minerals in surface soils where organic matter contents are higher than in subsoils. Complexation also inhibits the formation of $\mathrm{Al}(\mathrm{OH})_{4}^{-}$ and favors $\mathrm{AlO}_{2}^{-}$and the formation of boehmite. This could be why boehmite has been found in soils (Hsu, 1989). If the $\mathrm{pH}$ increases above neutrality ( $\mathrm{pH} \mathrm{7-12)}$, $\mathrm{OH}^{-}$can compete more effectively with the ligand for $\mathrm{Al}$ so polymerization becomes more prevalent and hence gibbsite may form. At even higher $\mathrm{pH}$ values $(>12)$, dehydration of $\mathrm{Al}(\mathrm{OH})_{4}^{-}$to oxo linkages will occur and boehmite will become the favored precipitate again (Hemingway, 1982).

If iron is present, thermodynamic considerations indicate that the simultaneous precipitation of goethite and gibbsite at $\mathrm{Si}$ activities less than that required for kaolinite precipitation can affect the reaction pathway by favoring the formation of Al-substituted goethite or hematite rather than pure Al hydrous oxides (Tardy and Nahon, 1985). Field evidence suggests that this could be important in some acidic soils. Fitzpatrick and Schwertmann (1982) found that the crystallinity of kaolinite and the Al substitution of ferric hydrous oxides in lateritic profiles increased with depth and with decreasing $\mathrm{pH}$. In contrast, equilibrium modeling indicates that $\mathrm{Al}$ contents of goethite tend to decrease as aridity and the concentration of $\mathrm{Si}$ in the soil solution increase (Tardy, 1971) and that Al-substituted goethite is thermodynamically more metastable than gibbsite at low activities of Al (Figs. 6a and 6c) (Tardy and Nahon, 1985). These predictions assume that ideal solid solutions can exist in soils and that they are in equilibrium with other Al minerals, such as kaolinite and gibbsite.

Solutions well-buffered with respect to $\mathrm{pH}$ increase the rate of precipitation of aluminum hydrous oxides (May et al., 1979) but do not affect the dissolution of feldspars (Wollast, 1967). For Al hydrous oxides, the reaction rate decreases as the difference between initial and final $\mathrm{pH}$ values gets larger in poorly buffered solutions, even if the solution is initially supersaturated with respect to a solid phase. 

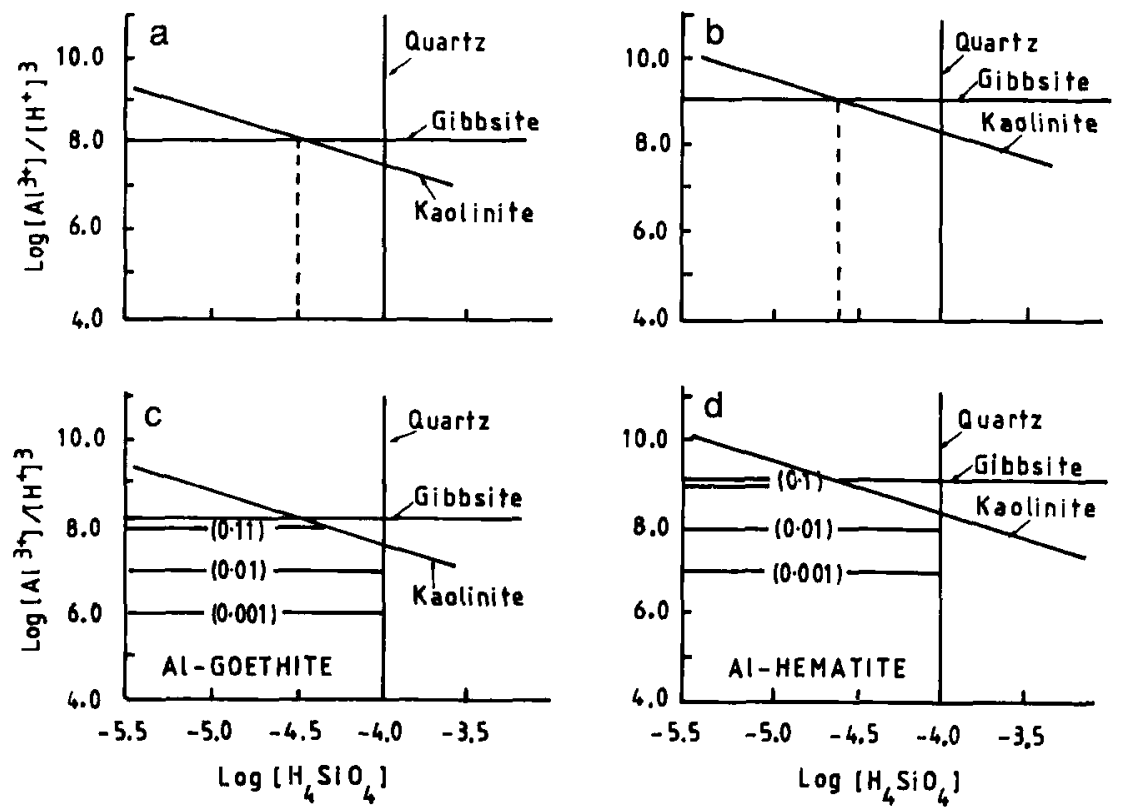

Figure 6 Equilibrium solubility diagram for gibbsite, quartz, and kaolinite at activities of water $\left(\mathrm{a}_{\mathrm{w}}\right)$ of 1.0 (a) and 0.5 (b) and for goethite (c) and hematite (d) with substituted $\mathrm{Al}$ varying from 0.001 to $0.1 \%$. (After Tardy and Nahon, 1985, Am. J. Sci., reprinted by permission of American Joumal of Science.)

Carbon dioxide may influence both the reaction pathway and rate. Increasing partial pressure of $\mathrm{CO}_{2}$ (as may occur in the rhizosphere) decreases the dehydration of $\mathrm{Al}(\mathrm{OH})_{4}^{-}$and favors the formation of gibbsite rather than boehmite (Hemingway, 1982). An increase in the level of dissolved $\mathrm{CO}_{2}$ may increase the $\mathrm{pH}$ buffering of the soil solution and affect the rate of reaction as discussed earlier.

Raising the temperature (as may occur in dry, hot weather experienced in arid and mediterranean climates) increases the rate of reaction and influences the reaction pathway by increasing the likelihood of dehydration of $\mathrm{Al}(\mathrm{OH})_{4}^{-}$to $\mathrm{AlO}_{2}^{-}$and changing the relative values of $\Delta G_{\mathrm{r}}^{\circ}$ of minerals that may form. For example, gibbsite converts to boehmite at $\mathrm{T}>368 \mathrm{~K}$ (Hemingway, 1982).

Polydispersity of a species in solution with respect to size or molecular weight can affect its dissolution (Parks, 1990). The smallest particles with the highest surface area tend to dissolve first but reprecipitate as more well-ordered, larger crystals. Hence a polydisperse system may take a lot longer to dissolve unless the rate of reprecipitation is much slower than the rate of dissolution.

Lowering the activity of water (as a soil dries or as water enters a smaller pore 
size) affects the reaction pathway, equilibrium activities of mineral components, and the composition of solid phases (Tardy and Nahon, 1985). Assuming that equilibrium is achievable, decreasing the activity of water increases the activity of $\mathrm{Al}^{3+}$ in equilibrium with hydrous $\mathrm{Al}$ oxides and decreases $\mathrm{Si}$ activity at which gibbsite and kaolinite are in equilibrium (Fig. 6). Lowering the activity of water favors the formation of diaspore and boehmite over gibbsite but this depends on the choice of the equilibrium constant (Fig. 7). Thermodynamic considerations indicate that the percentage of Al that can substitute in goethite or hematite, in equilibrium with kaolinite and quartz, increases as water activity decreases (Tardy and Nahon, 1985).

The influence of water activity on mineral solubility indicates that the formation of boehmite rather than gibbsite would be favored in dry soils, particularly with a large clay-sized fraction. Gibbsite would tend to precipitate in larger pores whereas boehmite would precipitate in smaller pores in which water activity would be lower. Alternatively, if $\mathrm{Si}$ was present, gibbsite precipitation would be more prevalent in large pores and channels whereas kaolinite would be more stable in the fine pores.

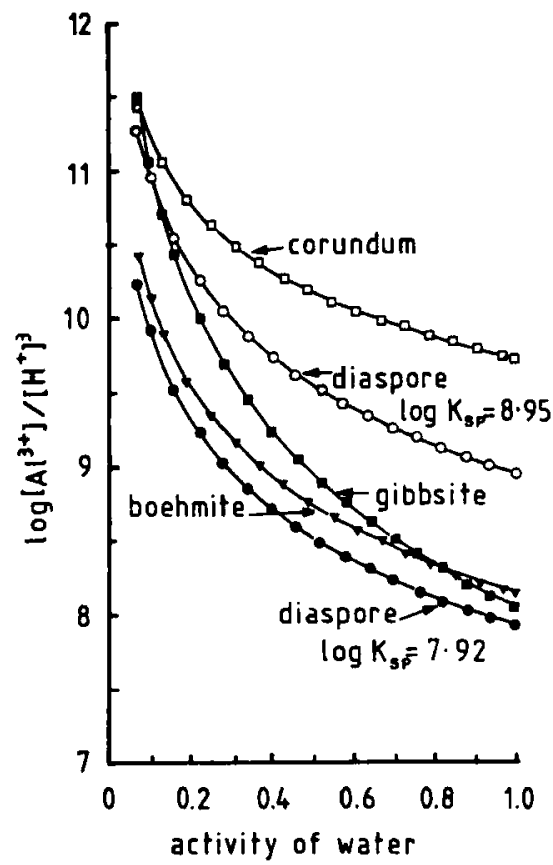

Figure 7 The relationship between $\log \left[\mathrm{Al}^{3+}\right] /\left[\mathrm{H}^{+}\right]^{3}$ and the activity of water $\left(\mathrm{a}_{\mathrm{w}}\right)$ for corundum $\left(\log K_{s p}=9.73\right)$, diaspore $\left(\log K_{s p}=7.92\right.$ or 8.95$)$, boehmite $\left(\log K_{s p}=8.13\right)$, and gibbsite $\left(\log K_{s p}\right.$ $=8.04)$. Log $K_{s p}$ values taken from Lindsay (1979) or Tardy and Nahon (1985). 


\section{B. Solid Properties}

The aggregation and composition of the bulk mineral and its surface layers will affect the composition of the solution and hence the reaction pathway and rate and surface morphology. It is still not clear which minerals dissolve congruently or incongruently and whether dissolution and precipitation occur through surface-controlled reactions or the development of leached layers. In addition, it has yet to be established unequivocally whether dissolution and precipitation occur at specific sites or uniformly across the surface of a mineral. These uncertainties all affect the activity of the solid and the quantity of soluble components in equilibrium with it. Solubility of a mineral decreases when the solid activity is $<$ l which may be due to inclusion or the mineral surface having concave interfaces rather than flat surfaces. Precipitation on to interlayers, lattice defects, convex interfaces, low crystallinity, and small grain size increase the activity of a solid above the ideal value of 1.0 (Tardy and Nahon, 1985; Sposito, 1981, 1989b; Schott, 1990).

Solubility increases with surface area which can result from increasing disorder (amorphous versus crystalline) or more structural defects (Parks, 1990). Pits, fractures, ledges, corners, and edges are all structural defects that may contribute to dissolution to different extents depending on the relative rates and qualities dissolved (Schott et al., 1989) (Fig. 8). The relative contribution of each defect to the overall dissolution of a mineral depends on the degree of saturation. For example, as relative saturation increases from values far less than unity (i.e., highly undersaturated), the fewer the sites at which a pit may form and hence the smaller the contribution of this process to overall dissolution (Schott $e t$ al., 1989). As dissolution proceeds, however, a decrease in surface strain energy at structural defects may counterbalance the increase in surface area and hence the increase in dissolution rate due to a high density of defects may not be as great as expected (Schott, 1990). In supersaturated solutions, amorphous materials tend to precipitate more quickly because the rough surface provides more sites for nucleation than the smooth surfaces of crystalline phases. Crystalline materials have a higher activation energy barrier to be overcome for precipitation to occur and a higher surface tension (or free energy) which limits solubility and decreases the dissolution rate (Van Straten et al., 1984). Hence, it is possible to have highly supersaturated solutions of sparingly soluble minerals. A less structured, higher specific surface and spongy solid phase would be expected to nucleate and grow a precipitate more quickly than a well-structured, low surface area solid.

The phrase "crystal ripening" was coined by Ostwald to describe the process by which small grains tend to dissolve to form fewer grains which are larger (Morse and Casey, 1988). This process tends to lead to a wider distribution in grain sizes as time progresses and thereby affects the rates of dissolution and 
What Determines Measured Dissolution Rate With Parallel Processes?

Fastest process is normally rate-determining unless its contribution to total dissolved concentration is insignificant
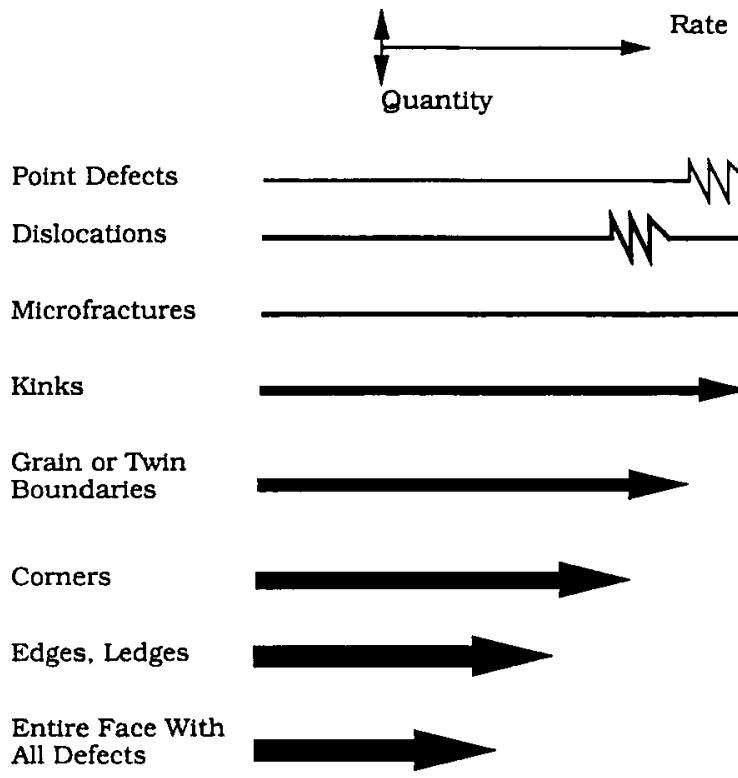

Figure 8 A schematic illustration of the parallel processes involved in crystal dissolution. The horizontal length of each arrow indicates the relative rate of each process (actual rates can differ by many orders of magnitude). The vertical thickness of each arrow represents the relative quantity of material dissolved and delivered to aqueous solution by that process. Thus, while point and linear defects react most rapidly, they deliver less dissolved material to solution than slower dissolution of faces and pits occurring at edges, ledges, and corners. (Reprinted from Geochim. Cosmochim. Acta, v. 53, Schott, J., Brantley, S., Crerar, D., Guy, C., Borcsik, M., and Williams, C., Dissolution kinetics of strained calcite, pp. 373-382, Copyright (1989), with kind permission from Pergamon Press, Ltd., Headington Hill Hall, Oxford OX3 OBW, UK.)

precipitation because of the dependence of solubility on grain size and because the rate of nucleation decreases with increasing surface tension.

Particle size also affects solubility because thermodynamics predicts that the heat of dissolution varies with particle size in different ways for different minerals. For example, hematite is less soluble than goethite at equal or large grain sizes, but more soluble when it is smaller (Tardy and Nahon, 1985). Similarly, amorphous silica is less soluble than quartz until the grain size of quartz become $<5 \mathrm{~nm}$ (Parks, 1990). However, if minerals have very small particle sizes, then these effects are minimal in comparison to those that alter precipitation and dissolution kinetics.

Adsorption of a solution component or the presence of a foreign surface can 
influence the kinetics of precipitation by affecting nucleation or crystal growth (Zhang and Nancollas, 1990). A certain level of supersaturation $\left(S_{\mathrm{m}}\right)$ has to be achieved before nucleation will occur, unless a foreign surface is present which can induce nucleation in the metastable region defined by $1<$ supersaturation $<$ $S_{\mathrm{m}}$. Adsorption can block precipitation sites on a nucleated surface and hence decrease crystal growth rates. However, if the adsorbate is similar in size to the lattice ion, it will promote growth.

The rates of dissolution and precipitation are a function of molecular structure, microtopography, transmissivity, and thickness of the surface layer (Casey and Bunker, 1990; Lasaga, 1990). The reactivity of a mineral and the probability of a monomer sticking to a surface increase as the roughness of the surface increases. Minerals with extensive cross-linking tend to dissolve slowly and incongruently to produce leached surface layers. The cross-links help to preserve the original structure once the leached ions have been released by hydration, hydrolysis, or ion exchange. Aluminum in octahedral arrangement is released more readily than tetrahedrally coordinated Al (Casey and Bunker, 1990). The extent to which leaching occurs depends on the mineral structure's rigidity and transmissivity to water and solutes. Once the leached layer has formed, it is just as dynamic as the interface between a solid and solution. Silanol groups may repolymerize and solution components can adsorb at specific sites or detach from the surface and they can diffuse along or into the leached layer (Hochella, 1990).

All these factors produce a surface that is unique and distinct from the bulk mineral and can have a significant effect on the reaction pathway and rates of dissolution and precipitation. Evidence for the presence of leached layers, precipitation on mineral surfaces, and incongruent dissolution was originally deduced from determination of components in solution or from spectroscopic techniques that are limited in their ability to distinguish between the composition of a surface and the bulk mineral. Since then spectroscopic and microscopic methods that can identify changes in structure at the molecular level initially indicated that leached layers or precipitated coatings did not occur; dissolution was controlled by surface reactions rather than diffusion; and that surface reactions did not occur uniformly over the surface but at weak points in the mineral structures (Mogk, 1990). Incongruent dissolution was considered to be due to the dissolution process not occurring uniformly over the surface and some of the data was interpreted as leached layers occurring nonuniformly, suggesting that the rate of dissolution depended on the number of reactive sites rather than the total surface area (Mogk, 1990). However, the approaches used were unable to measure the thickness of the reactive layer directly but had to estimate it from mass balance calculations or from the path length of the excited electrons in the spectroscopic technique used.

Even more recent studies have included techniques that can directly measure elements in the surface of minerals in layers that are as thin as $1 \mathrm{~nm}$ (Mogk, 1990; Hochella, 1990; Brown, 1990). These methods have confirmed that incon- 
gruent dissolution occurs but have not found evidence for dissolution being controlled by surface reactions. Compositional changes as a function of depth up to $100 \mathrm{~nm}$ can also be detected but interpretation of the data is limited by the method of collection which assumes that every surface component has been identified and that they can be expressed as a function of the sum of all the components (i.e., normalized data). This means that an apparent decrease in the relative concentration of one component may be an artifact of a large increase in the relative concentration of another component.

Aggregation of mineral particles decreases the dissolution rate of montmorillonite possibly by changing the rate-limiting step from surface complexation to diffusion of the dissolution products through the aggregate (Furrer $e t$ al., 1993).

\section{MODELING SOLUBLE ALUMINUM}

Attempts to model $\mathrm{Al}$ dissolution and precipitation have been fragmentary even though the effect of the factors described in the previous section has been reasonably well known for some time. A major limitation has been the lack of appropriate data with which to test models.

This section considers the development of models that predict solution composition in a general way rather than just models relating specifically to Al. Models developed by researchers in the field of acidic precipitation (Cosby et al., 1985; Furrer $e t$ al., 1990) are not necessarily based on dissolution and precipitation alone and are considered elsewhere (Eary et al., 1989; Ritchie, 1994).

Models have been developed for both open and closed systems and are based on thermodynamics and/or kinetics as related to the three components in the framework of Fig. 1. Models of surface morphology that are purely descriptive in nature, rather than predictive, also exist and have been reviewed by Hochella (1990) and references therein.

Each model has limitations and assumptions. Their accuracy depends on the derivation and choice of constant parameters and analytical errors in the experimental data used to develop them (May et al., 1986; Nordstrom and May, 1989; Hemingway and Sposito, 1989). It is not within the scope of this review to discuss these aspects of the models in great detail, but examples of the effects of different sources of inaccuracy on the predictive ability of models will be given.

\section{A. Chemical Thermodynamic Approaches}

The application of chemical thermodynamics to predicting solution quantities of mineral components has been a popular approach for many years (Garrells and 
Christ, 1965; Helgeson, 1968; Lindsay, 1979; Hemingway, 1982). Initially, it was assumed that the rate of precipitation was greater than the rate of dissolution and so equilibrium conditions prevailed instantaneously. The roles of irreversible and partial equilibrium thermodynamics were then considered as well as the existence of metastable minerals.

\section{Equilibrium Thermodynamics Models}

Models based on equilibrium thermodynamics have been the most commonly used approach to predicting Al quantities in soil solutions (Lindsay, 1979). This approach develops mass balance equations for each component in solution along with the equation for conservation of neutrality. The equations are written in terms of the free form of each component (e.g., $\mathrm{Al}^{3+}$ ) and the equilibrium constant that defines the formation of a mineral or soluble species. They are solved simultaneously, usually using the Newton-Raphson method, and predict which solid is controlling the soluble quantities of a mineral component and the solution speciation of that component (Sposito, 1981). The data required to use this type of model are given in Table II along with the major assumptions and limitations of its use.

Commonly, the activities of $\mathrm{H}^{+}, \mathrm{Al}^{3+}$, and $\mathrm{H}_{4} \mathrm{SiO}_{4}$ in a soil solution are compared to those values which are in equilibrium with certain well-defined minerals such as gibbsite, kaolinite, or muscovite. Solubility diagrams are constructed to estimate whether a particular mineral is controlling soluble $\left(\mathrm{Al}^{3+}\right)$. Equations defining the solubility product constant in terms of the ion activity product can be rearranged to express $\left(\mathrm{Al}^{3+}\right)$ in terms of $K_{s p}$. For example, Eq. (2) becomes:

$$
\log \left(\mathrm{Al}^{3+}\right)=8.04-3 \mathrm{pH},
$$

where $\log K_{s p}=8.04$. If $\log \left(\mathrm{Al}^{3+}\right)$ is plotted versus $\mathrm{pH}$, we achieve the variation in $\left(\mathrm{Al}^{3+}\right.$ ) with $\mathrm{pH}$ when $\mathrm{Al}(\mathrm{OH})_{3}$ (with $\log K_{s p}=8.04$ ) is in equilibrium with the solution phase. The activity of $\mathrm{Al}^{3+}$ and $\mathrm{pH}$ in a soil solution may be estimated analytically and then plotted on the above solubility diagram. If the data point falls on the solubility line then it could possibly be assumed that the mineral is controlling soluble $\mathrm{Al}^{3+}$, but this assumption is by no means unequivocal (Sposito, 1986). The soil solution would be undersaturated or oversaturated with respect to $\mathrm{Al}(\mathrm{OH})_{3}$ if it falls under or above the line, respectively. If the soil solution data points are in close proximity to a solubility line, it is sometimes assumed that that mineral is controlling $\left(\mathrm{Al}^{3+}\right)$ in solution. Small variations in equilibrium constants, errors in $\mathrm{pH}$ measurement, and small divergences of the actual data point from a solubility line can lead to large errors in predicting the soluble activity of $\mathrm{Al}^{3+}$ (Tables III-V). The apparently small divergences are a result of the logarithmic representation of data in solubility diagrams obscuring 


\section{Table II}

\section{Thermodynamically Based Models for Predicting Al Quantities in Solution}

\begin{tabular}{|c|c|c|c|c|}
\hline Model & Emphasis & $\begin{array}{c}\text { Thermodynamic } \\
\text { basis }\end{array}$ & Data required & Assumptions/limitations \\
\hline $\begin{array}{l}\text { Equilibrium } \\
\text { (Garrels and Christ, } \\
\text { 1965; Lindsay, } \\
\text { 1979) }\end{array}$ & $\begin{array}{l}\text { Solution com- } \\
\text { position }\end{array}$ & $\begin{array}{l}\text { Equilibrium mass bal- } \\
\text { ance, conservation of } \\
\text { neutrality }\end{array}$ & $\begin{array}{l}\text { Solution concentrations, } \\
\text { pH, 1, redox poten- } \\
\text { tial, mineral phases } \\
\text { present }\end{array}$ & $\begin{array}{l}\text { (i) Equilibrium achieved } \\
\text { (ii) All solution species have been identified } \\
\text { (iii) Experimental accuracy of data } \\
\text { (iv) Choice of equilibrium constants } \\
\text { (v) Kinetics and surface morphology not considered } \\
\text { (vi) Factors } 2,5,11,13-23 \text { in Table I not accounted for }\end{array}$ \\
\hline $\begin{array}{l}\text { Quasi-equilibrium } \\
\text { (Helgeson, 1968) }\end{array}$ & As above & $\begin{array}{l}\text { Equilibrium mass bal- } \\
\text { ance, irreversible } \\
\text { mass balance }\end{array}$ & As above & $\begin{array}{l}\text { (i) Partial equilibrium achieved for intermediary phases } \\
\text { (ii) Equilibrium for final secondary mineral } \\
\text { (iii) Only one reaction pathway } \\
\text { (iv) As for iii-vi }\end{array}$ \\
\hline $\begin{array}{l}\text { Nonequilibrium } \\
\quad \text { (Hemingway, 1982) }\end{array}$ & As above & As above & As above & $\begin{array}{l}\text { (i) As for iii-vi for first model } \\
\text { (ii) Does not recognize irreversible reactions explicitly } \\
\text { (iii) Only applies to closed systems }\end{array}$ \\
\hline
\end{tabular}


Table III

Variation in the Activity of $\mathrm{Al}^{3+}(\mu M)$ with Error in the Slope of the Solubility Curve for Gibbsite $(\mathrm{pAl}=3 \mathrm{pH}-\mathbf{8 . 0 4})$

\begin{tabular}{cccccccc}
\hline & & \multicolumn{7}{c}{$\mathrm{pH}$} \\
$\begin{array}{ccccccc}\text { Error in } \\
\text { slope (\%) }\end{array}$ & $\begin{array}{c}\text { Value of } \\
\text { slope }\end{array}$ & 4.013 & 4.188 & 4.214 & 4.246 & 4.347 & 4.68 \\
\hline 0 & 3 & 100 & 30.0 & 25.0 & 20.0 & 10.0 & 1.00 \\
1 & 2.97 & 132 & 40.0 & 33.5 & 26.8 & 13.5 & 1.38 \\
3 & 2.90 & 253 & 78.5 & 66.0 & 53.2 & 27.2 & 2.90 \\
10 & 2.70 & 1603 & 540 & 459 & 376 & 201 & 25.4 \\
15 & 2.55 & 6410 & 2294 & 1969 & 1629 & 902 & 128 \\
\hline
\end{tabular}

Table IV

Variation in the Activity of $\mathrm{Al}^{3+}(\mu M)$ Predicted by Theoretical Gibbsite Solubility Caused by Errors in pH of \pm 0.1 Unit $\left(\log K_{s p}\right.$ Gibbsite $\left.=8.04\right)$

\begin{tabular}{lccr}
\hline & \multicolumn{3}{c}{ Error in $\mathrm{pH}$} \\
\cline { 2 - 4 } $\mathrm{pH}$ & 0 & +0.1 & -0.1 \\
\hline 4.188 & 30 & 15.0 & 59.7 \\
4.214 & 25 & 12.5 & 49.5 \\
4.347 & 10 & 5 & 19.9 \\
\hline
\end{tabular}

Table V

Variation in the Activity of $\left(\mathrm{Al}^{3+}\right)$ Caused by Errors in the Estimation of $\log K_{s p}$ for Gibbsite Dissolution

\begin{tabular}{|c|c|c|c|c|}
\hline \multirow{2}{*}{$\begin{array}{c}\text { Error in log } \\
K_{s p}(\%)\end{array}$} & \multirow{2}{*}{$\begin{array}{l}\log \\
K_{s p}\end{array}$} & \multicolumn{3}{|c|}{$\mathrm{pH}$} \\
\hline & & 4.347 & 4.246 & 4.214 \\
\hline+5 & 8.442 & 253 & 50.6 & 63.2 \\
\hline+2 & 8.201 & 14.5 & 29.0 & 36.3 \\
\hline+1 & 8.120 & 12.1 & 24.1 & 30.2 \\
\hline 0 & 8.040 & 10.00 & 20.0 & 25.0 \\
\hline-1 & 7.960 & 8.32 & 16.7 & 20.8 \\
\hline-5 & 7.638 & 3.97 & 7.94 & 9.91 \\
\hline-10 & 7.236 & 1.57 & 3.15 & 3.93 \\
\hline
\end{tabular}


the large deviations in the predicted activity caused by the limitations and assumptions in Table II and are discussed in the previous section.

Another approach to deducing the phase-controlling soluble Al using equilibrium thermodynamics is to estimate the relative saturation (RS) or the saturation index (SI) for different $\mathrm{Al}$-containing minerals. Inferences that $\mathrm{RS}=1$ and $\mathrm{SI}=$ 0 indicate that a particular mineral is controlling soluble $\mathrm{Al}$, suffer from the same limitations as mentioned earlier for deductions made from solubility diagrams. Similarly, it may be tempting to say $\mathrm{SI}=0.2$ is close enough to zero to represent equilibrium. However, it is equivalent to a 0.2 change in $K_{s p}$ which results in approximately a $50 \%$ change in $\left(\mathrm{Al}^{3+}\right)$ (Table $\mathrm{V}$ ).

The size of the errors in predicting $\left(\mathrm{Al}^{3+}\right)$ has important implications for plant growth. In nutrient solutions, activities of $\mathrm{Al}^{3+}$ as low as $2 \mu M$ are toxic to barley (Cameron et al., 1986). In the field, estimates of toxic Al for the subsoil of yellow earths of Western Australia show that $\mathrm{Al}>30 \mu \mathrm{M}$ measured in a $0.005 \mathrm{M}$ $\mathrm{KCl}$ extract are toxic to wheat (Carr et al., 1991). A $1 \%$ error in slope (Table III), a 0.1 unit error in pH (Table VI), or a $2 \%$ error in the $\log K_{s p}$ value (Table V) can result in an erroneous prediction of toxicity in the $\mathrm{pH}$ range of 4.2-4.25 if one assumes gibbsite is controlling $\mathrm{Al}$ solubility. A $1 \%$ error in the slope of the solubility line at $\mathrm{pH} 4.0-4.35$ is equivalent to a $2.5-3 \%$ error in $\log \left(\mathrm{Al}^{3+}\right)$ which is often assumed to be accurate enough for the purpose of predicting $\left(\mathrm{Al}^{3+}\right)$ in soils. However, a $2.5-3 \%$ variation in $\log \left(\mathrm{Al}^{3+}\right)$ is equivalent to a $33-35 \%$ error in $\left(\mathrm{Al}^{3+}\right)$ which at $\mathrm{pH} 4.2$ is sufficient to change $\left(\mathrm{Al}^{3+}\right)$ from a nontoxic to a toxic value for the yellow earth soils studied by Carr et al. (1991). The size of these errors increases as $\mathrm{pH}$ decreases.

The inaccuracies in predicting $\left(\mathrm{Al}^{3+}\right)$ that arise from not identifying all the complexing ligands in solution depend on the $\mathrm{pH}$, the equilibrium constant (log $K^{\circ}$ ) for $\mathrm{Al}$ reacting with the unknown ligand $(\mathrm{L})$ and the activity of the unknown ligand relative to that of $\mathrm{Al}^{3+}$ (Figs. 9 and 10). The concentrations of $\mathrm{Al}$ species in Figs. 9 and 10 were estimated using an equilibrium program, TITRATOR (Cabaniss, 1987), assuming a hypothetical case in which $\mathrm{Al}(\mathrm{OH})^{2+}, \mathrm{Al}(\mathrm{OH})_{2}{ }^{+}$, $\mathrm{Al}(\mathrm{OH})_{3}, \mathrm{Al}-\mathrm{L}$, and $\mathrm{HL}$ were the species formed in solution. $\log \mathrm{K}^{\circ}$ values were taken from Lindsay (1979) except for Al-L and HL ( $\left.\log K^{\circ}=3\right)$; ionic strength was set at zero and the total concentration of $\mathrm{Al}$ was $30 \mu \mathrm{M}$. The ligand concentration was $30 \mu M$ unless the $\mathrm{L}: \mathrm{Al}$ ratio varied between 1 and 3.3. At $\mathrm{pH}$ 4.5 (Fig. 9a), as the $\log K^{\circ}$ for Al- $\mathrm{L}$ increases from 3.2 (a weakly complexing ligand) to 6.98 (a strongly complexing ligand), $\left(\mathrm{Al}^{3+}\right)$ decreases from 50 to $<5 \%$ of total soluble $\mathrm{Al}, \mathrm{Al}_{\mathrm{T}}$, when equivalent concentrations of $\mathrm{Al}_{\mathrm{T}}$ and $\mathrm{L}$ are present. At pH 4.0 (Fig. 9b), the trend is similar except that $\left(\mathrm{Al}^{3+}\right)$ is $84 \%$ of $\mathrm{Al}_{\mathrm{T}}$ at the initial $\log K^{\circ}$ of 3.2 . Increasing the ratio of a strongly complexing ligand and $\mathrm{Al}$ from 1 to 3.3 has little effect on $\left(\mathrm{Al}^{3+}\right)$ because it is a minor proportion of $\mathrm{Al}_{\mathrm{T}}$. At the other extreme, increasing the $\mathrm{L}: \mathrm{Al}$ ratio for a weakly complexing ligand also does not change $\left(\mathrm{Al}^{3+}\right)$ by more than $7 \%$ simply because of the low 
Table VI

Kinetically Based Models for Predicting Al Quantities in Solution

\begin{tabular}{|c|c|c|c|c|c|c|}
\hline \multirow[b]{2}{*}{ Model } & \multirow[b]{2}{*}{ Emphasis } & \multicolumn{2}{|c|}{ Theoretical basis } & \multirow[b]{2}{*}{ Data required } & \multirow{2}{*}{\multicolumn{2}{|c|}{ Assumptions/limitations }} \\
\hline & & Thermodynamics & Kinetics & & & \\
\hline Pačes (1978) & $\begin{array}{l}\text { Solution com- } \\
\text { position }\end{array}$ & $\begin{array}{l}\text { Equilibrium (E) } \\
\text { Quasiequilibrium } \\
\quad(\mathrm{QE}) \\
\text { Irreversible (IR) }\end{array}$ & $\begin{array}{l}\text { Crystal growth- } \\
\text { differential rate } \\
\text { law (CG-DRL) } \\
\text { Transport (T) }\end{array}$ & $\begin{array}{l}\text { Solution concentrations, } \\
\mathrm{pH}, \mathrm{I}\end{array}$ & $\begin{array}{l}\text { (i) } \\
\text { (ii) } \\
\text { (iii) } \\
\text { (iv) } \\
\text { (v) } \\
\text { (vi) } \\
\text { (vii) }\end{array}$ & $\begin{array}{l}\text { All solution species have been identi- } \\
\text { fied } \\
\text { Experimental accuracy of data } \\
\text { Choice of equilibrium constants } \\
\text { Factors } 2,5,11,13-23 \text { in Table I not } \\
\text { accounted for } \\
\text { Surface morphology not considered } \\
\text { Formation of an activated complex not } \\
\text { explicity recognized } \\
\text { Does not include nucleation, epitaxy, } \\
\text { or crystal ripening }\end{array}$ \\
\hline $\begin{array}{l}\text { Van Straten et al. } \\
\quad \text { (1984) }\end{array}$ & Precipitation & $\mathbf{E}$ & $\begin{array}{l}\text { CG-DRL nucleation } \\
\text { (N) }\end{array}$ & As above & (i) & $\begin{array}{l}\text { All solution and surface species have } \\
\text { been identified } \\
\text { Does not include crystal ripening }\end{array}$ \\
\hline $\begin{array}{l}\text { Stumm and Wiel- } \\
\text { and (1990) }\end{array}$ & Dissolution & $\mathrm{E}$ & $\begin{array}{l}\text { CG-transition state } \\
\text { theory (CG-TST) }\end{array}$ & $\begin{array}{l}\text { As above measured before } \\
\text { and after adsorption of } \\
\mathrm{H} / \mathrm{OH} \text { and ligands }\end{array}$ & $\begin{array}{l}\text { (i) } \\
\text { (ii) } \\
\text { (iii) } \\
\text { (iv) } \\
\text { (v) } \\
\text { (vi) }\end{array}$ & $\begin{array}{l}\text { All solution and surface species have } \\
\text { been identified } \\
\text { As for ii-iv and vii for first model } \\
\text { System is far from equilibrium } \\
\text { Surface area does not change } \\
\text { Active sites are instantly regenerated } \\
\text { Active sites/total sites } \ll 1\end{array}$ \\
\hline $\begin{array}{l}\text { Nagy and Lasaga } \\
\text { (1992) }\end{array}$ & $\begin{array}{l}\text { Dissolution/ } \\
\text { precipitation }\end{array}$ & E, QE, IR & CG-TST, N & As for first model & $\begin{array}{l}\text { (i) } \\
\text { (ii) }\end{array}$ & $\begin{array}{l}\text { As for i-iv for first model } \\
\text { Does not include epitaxy or crystal } \\
\text { ripening explicitly }\end{array}$ \\
\hline $\begin{array}{l}\text { Steefel and Van } \\
\text { Capellan (1990) }\end{array}$ & $\begin{array}{l}\text { Dissolution/ } \\
\text { precipitation }\end{array}$ & E, QE, IR & CG-DRL, N & As for first model & (i) & As for $\mathrm{i}-\mathrm{iv}$ for first model \\
\hline
\end{tabular}



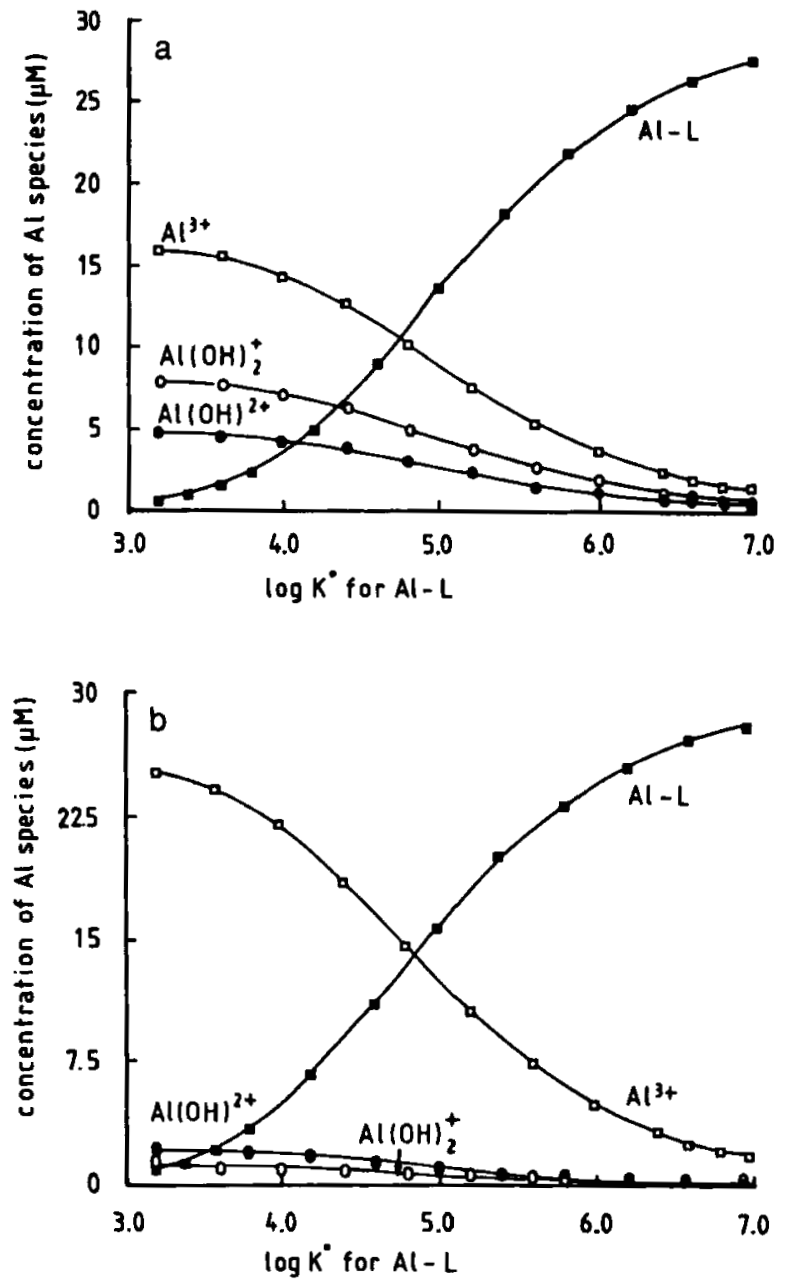

Figure 9 The variation in concentration of $\mathrm{Al}^{3+}, \mathrm{Al}(\mathrm{OH})^{2+}, \mathrm{Al}(\mathrm{OH})_{2}{ }^{+}$, and $\mathrm{Al}-\mathrm{L}$ with $\log \mathrm{K}^{\circ}$ for $\mathrm{Al}-\mathrm{L}$ at $\mathrm{pH} 4.5$ (a) and $\mathrm{pH} 4.0$ (b). $\mathrm{Al}_{\mathrm{T}}=\mathrm{L}_{\mathrm{T}}=30 \mu \mathrm{M}$.

$\log K^{\circ}$ (data not shown). The biggest effect of $\mathrm{L}: \mathrm{Al}$ ratios on $\left(\mathrm{Al}^{3+}\right)$ occurs when ligands with medium binding strength $\left(\log K^{\circ} \approx 5\right.$ ) are present (Fig. 10). In this case, $\left(\mathrm{Al}^{3+}\right)$ decreases from 41 to $13 \%$ of $\mathrm{Al}_{\mathrm{T}}$ as the $\mathrm{L}$ : $\mathrm{Al}$ ratio changes from 1 to 3.3.

\section{Quasi- and Nonequilibrium Thermodynamic Approaches}

The limitations of equilibrium thermodynamics even within a closed system led some workers to consider irreversible reactions, partial equilibria, and meta- 


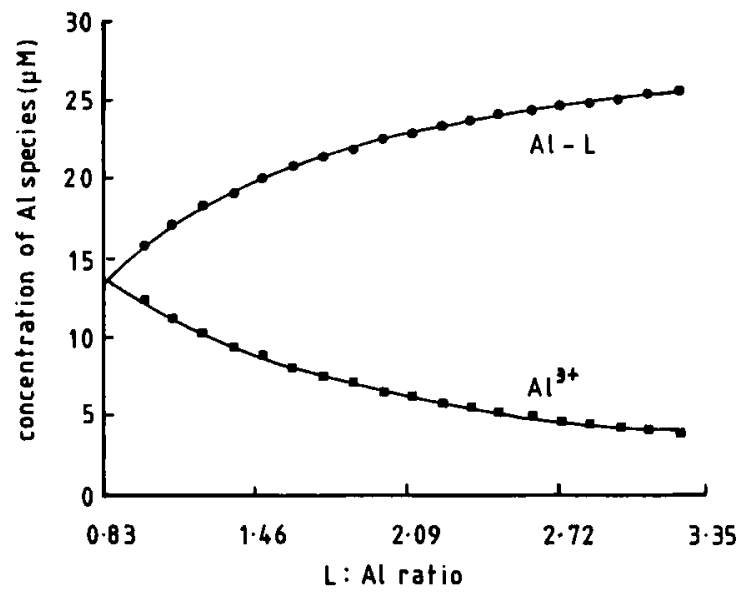

Figure 10 The variation in concentration of $\mathrm{Al}^{3+}$ and $\mathrm{Al}-\mathrm{L}$ with the ratio of $\mathrm{L}: \mathrm{AL}$ at $\mathrm{pH} 4$. $\mathrm{Al}_{\mathrm{T}}=30 \mu M$ and $\log K^{\circ}$ for $\mathrm{Al}-\mathrm{L}=5.00$.

stable solids. Helgeson (1968) considered that the dissolution of a mineral in a soil or rock to be an irreversible reaction resulting in the formation of one or more minerals in an equilibrium state. Before the final stage is reached, a series of compounds may form which only achieve partial equilibrium in the system, but each state is reversible with respect to the next. The major assumption of such a model is that there is only one reaction pathway and that it is deduced from the initial and final states of the system. In addition, the model does not describe the process over long enough time periods for equilibrium to be achieved for some final phases, e.g., systems described by this model are often supersaturated with respect to quartz, even if equilibrium has been achieved between the dissolving phase (pyrophyllite) and another final phase, kaolinite (Helgeson, 1968). The models also have limitations in common with equilibrium models (Table II).

In reality, the formation of stable secondary minerals is irreversible and the composition of a solution depends on the irreversible reactions as well as the equilibrium mass balance equations for reversible reactions that produced metastable minerals. This approach to describing equilibrium precipitation and dissolution processes was formalized by Ostwald as long ago as 1897 (Hemingway, 1982). The law of successive reactions quantifies the common observation that unstable forms of minerals frequently precipitate before a stable form. The law points out that when a mineral dissolves, the first new phase to precipitate will be the mineral that has a free energy nearest to that of the dissolving mineral rather than the solid phase that has the lowest free energy. If several mineral phases exist with intermediary values of free energy, then each one will precipitate successively, in order of decreasing free energy, with the most thermo- 
dynamically stable mineral precipitating last. Ostwald's observation is not a universal law. It simply recognizes that intermediary phases with simple structures tend to form before more complex minerals with a lower free energy. This law represents only one of many possibilities. Attempts to derive it from a rigorous thermodynamic standpoint are inappropriate because there is no evidence that the pathway of precipitation has to include several metastable phases (Morse and Casey, 1988). The extent to which intermediary phases form and persist depends on the initial species in solution and the relative rates of formation of all the metastable and final phases in relation to their free energy state. This model can be qualitatively applied to explain why the numerous studies of Al precipitation differ in their conclusions as to which mineral phase is formed and to explain why solutions can remain supersaturated with respect to gibbsite (the most stable $\mathrm{Al}-\mathrm{H}_{2} \mathrm{O}$ mineral) for months or even years (Hemingway, 1982).

From theoretical considerations, one would expect $\mathrm{Al}$ to precipitate out of solution to successively produce the following mineral phases:

amorphous $\mathrm{Al}(\mathrm{OH})_{3} \rightarrow$ bayerite $\rightarrow$ nordstrandite $\rightarrow$ boehmite $\rightarrow$ gibbsite $\rightarrow$ diaspore,

assuming the thermodynamic equilibrium constants quoted by Lindsay and Walthall (1989) are appropriate. In published experiments, however, each phase is not necessarily observed, because varying experimental conditions change the $\mathrm{Al}$ species in solution, which may favor the formation of one phase more than another. For example, anything (e.g., pH, temperature) that promotes the formation of $\mathrm{AlO}_{2}^{-}$linkages as opposed to $\mathrm{Al}(\mathrm{OH})_{4}^{-}$bonds will favor the formation of $\mathrm{AlOOH}$ minerals rather than $\mathrm{Al}(\mathrm{OH})_{3}$ phases. In reality, mineral phases that are not the most thermodynamically stable are observed in soils (e.g., boehmite; Hsu, 1989) and weathered rock, and soil solutions and water samples are often found to be supersaturated. Both these observations point to the long times (tens of thousands of years) required for progression down the pathway from the irreversibly dissolving mineral grain to the precipitation of the most thermodynamically stable secondary mineral.

\section{B. Kinetic Approaches to Modeling}

There are many kinetic approaches to modeling precipitation and dissolution (Sparks, 1989). In the context of this review, chemical kinetics refers to the rate of chemical reactions where transport is not limiting. Nonchemical kinetics refers to the rate of transport of reactant and products in the bulk solution or at the solid-solution interface. In soils, both types of kinetics occur simultaneously and are not necessarily differentiated appropriately in some research (Skopp, 1986).

The rate of precipitation or dissolution may be surface controlled, transport 
controlled, or a combination of both (Lasaga, 1990). In the geochemical literature, movement of reactants or products toward and away from a surface is considered to be so rapid that it is not usually the rate-determining step and tends to be ignored in models. The rate of reaction and detachment at the surface are considered to be the major mechanisms controlling dissolution and precipitation (Stumm and Wollast, 1990). However, in soil acidity research, we need to be more circumspect because one exception to this general behavior is the dissolution of gypsum which can be used as an ameliorant for acidic subsoils (Berner, 1978).

Chemical kinetic models may be based on general differential rate laws, transition state theory, crystal growth, or nucleation (Walton, 1967; Sparks 1989). Nonchemical models include parabolic rate laws that can describe diffusion near a precipitating or dissolving surface as the rate-limiting step and algorithms that consider water flow through soil profiles (Skopp, 1986; Sparks, 1989).

Empirical rate laws describe the rate of dissolution or growth in terms of the extent of saturation of the solution and a rate constant or coefficient, $k$. The mechanism(s) may be inferred from the shape of the relationship and from changes in the shape brought about by varying the initial driving force for the reaction. In their simplest form, they apply to elementary reactions in which the reactants $A$ and $B$ combine to form a product $C$ without precursors being formed in an intermediary phase (Sparks, 1989):

$$
A+B \rightarrow C
$$

This interpretation assumes that $k$ is a rate constant that only varies with temperature and pressure. Unfortunately, reactions in soils appear to be far from elementary and hence empirical rate laws may not be strictly appropriate for describing Al solubility in soils. This drawback also applies to transition state theory. However, a more flexible approach is to look upon $k$ as a coefficient which can also depend on factors such as surface area, the free energy change of the reaction, or the concentration of precursors (Nagy and Lasaga, 1992). Alternatively, some of these parameters can be stated explicitly in the rate equation (Pačes, 1978; Steefel and Van Capellan, 1990; Nagy and Lasaga, 1992). The applicability of these types of models involves assumptions and limitations common to other approaches (Table VI) but varies quite widely, depending on how many parameters that affect $k$ are stated explicitly in the model.

A general rate law can be used to model soluble $\mathrm{Al}$ by assuming that both the dissolution of the primary mineral and precipitation of the secondary mineral are irreversible reactions and that metastable intermediary mineral phases may also form (Pačes, 1978). The model can apply to both closed and open systems and therefore recognizes that the solution composition will be influenced by the speed of percolating water in the soil profile. As pointed out by the author, most published data contain insufficient detail to test the model and therefore Pačes 
(1978) was only able to use it to consider the nature of reversible metastable solids that could be controlling $\mathrm{Al}$ and $\mathrm{Si}$ in natural waters. Using data from 152 sets of field and laboratory data, he postulated that the presence of a metastable aluminosilicate was best able to explain soluble $\mathrm{Al}$ in the natural waters being studied. The form of the mineral varied with $\mathrm{pH}$ such that the solubility product, $K_{s p}=10^{-5.89}+1.59 \mathrm{pH}$.

Implicit in the Ostwald law of successive reactions is that the rate of reaction of each successive step is slower. The total free energy of a reaction $\left(\Delta G_{\mathrm{r}}\right)$ has three components:

i. The standard free energy of a reaction in an ideal system, $\Delta G_{\mathrm{r}}{ }^{\circ}$;

ii. the surface-free energy of precipitate growth; and

iii. the surface-free energy of nucleation.

The surface-free energy may represent a major proportion of the total free energy of a reaction and hence the equilibrium thermodynamic contribution becomes less important and supposedly metastable phases precipitate first before stable phases. Hence the Ostwald law may also be modeled from a kinetic point of view that considers morphological features of the surface (Table VI) (Van Straten et al., 1984). Accordingly, the kinetic rule of stages predicts the sequence of mineral precipitation from the steady-state rate of nucleation which increases with the number of collisions by which a critical nucleus evolves from monomeric species and decreases with the free energy difference, $\Delta G_{c}$, that measures the reversible work required for the formation of a nucleus. The free energy difference increases with increasing interfacial tension and decreasing saturation of the solution with respect to a particular mineral.

The induction time as well as the rate of nucleation needs to be considered when attempting to explain or predict a precipitation sequence. The induction time is the period before a steady state is reached for the nucleation rate, and it increases as the free energy of formation of a surface, $\Delta G_{c}$, increases.

The more disordered the surface structure (i.e., more amorphous) the shorter the induction time because the roughness of the surface enhances the probability of a monomer sticking to the surface. Hence, an amorphous material may precipitate before a crystalline phase because it has a smaller induction time even though the crystalline phase may have a higher nucleation rate due to the solution being more supersaturated with respect to the crystalline phase. Van Straten et al. (1984) used this model to explain the sequence of precipitation of aluminum hydroxide phases from potassium aluminate solutions that varied in their extent of supersaturation but had the same $\mathrm{pH}$. At high supersaturation $(\mathrm{pH}+\mathrm{pAl}$ $\leq 12$, poorly crystalline boehmite precipitated before bayerite because the former mineral has a less-ordered structure and hence a lower induction time. Bayerite is thermodynamically less stable than poorly crystalline boehmite and would be predicted to precipitate first if one considered supersaturation without 
the effect of induction times. When supersaturation was low $(\mathrm{pH}+\mathrm{pAl}$ $>12.55$ ), only bayerite formed presumably because the induction times were similarly large.

The parabolic rate law predicts that the concentration in solution of mineral components is linearly related to the square root of time. However, the application of the law has been the subject of much debate [see Velbel (1986) and Sparks (1989), and references therein] because it implies that the rate of dissolution is transport controlled and this process is not considered to be a major mechanism by many workers (Stumm and Wieland, 1990). A linearity between concentration and the square root of time has been observed for Al-containing minerals such as feldspar but the correlation can be explained by mechanisms other than diffusion control (Nielsen, 1986; Velbel, 1986; Sparks, 1989). A parabolic relationship can result from the formation of a surface layer that increases in thickness with time; the adherence of finer particles onto mineral surfaces after grinding is used in sample preparation; nonstoichiometric dissolution; the linear release of mineral components followed by their nonlinear precipitation as secondary minerals; changes in parameters (e.g., $\mathrm{pH}, \mathrm{CO}_{2}$ ) thought to be constant; and a surface spiral mechanism of dissolution. Irrespective of the differences in interpretation of this law, the limitations and assumptions of its use given in Table VI indicate that it is of limited value for predicting solution composition unless combined with other kinetic or thermodynamic approaches.

The chemical kinetic rate law may also be written in terms of the Gibbs free energy of the reaction, $\Delta G_{\mathrm{r}}$ (Nagy and Lasaga, 1992). In this approach, the rate of dissolution or precipitation is not only proportional to the rate coefficient and activities of the species in the rate-determining step but also is proportional to a function of $\Delta G, f\left(\Delta G_{\mathrm{r}}\right)$. The function can depend on defect properties and densities, precipitation of intermediary phases, the irreversibility of the reactions, and changes in surface and solution speciation. The rate coefficient was assumed to be dependent on temperature, pressure, the reactive surface area, and the concentrations of reactants and other unaccounted effects of the properties of the solution. For elementary reactions, dissolution becomes independent of $\Delta G_{\mathrm{r}}$ far from equilibrium but for reactions with more than one step, the variation of the rate of dissolution or precipitation with $\Delta G_{\mathrm{r}}$ is more complex.

Much of the research and modeling of dissolution and precipitation rates into aluminosilicates and aluminum hydrous oxides have been carried out on systems far from equilibrium, and it has been assumed (implicitly or explicitly) that the mechanism controlling precipitation or dissolution does not vary with the extent of saturation of the solution, i.e., proximity to equilibrium. The model developed by Nagy and Lasaga (1992) takes this possibility into account by the inclusion of $\Delta G_{\mathrm{r}}$ in the rate equation. Their work has shown that the values of $\Delta G_{\mathrm{r}}$ can vary enormously with the saturation state of the solution and hence illustrates the dangers of estimating rates of dissolution or precipitation in sys- 
tems far from equilibrium and assuming that they are still applicable for solutions near to equilibrium. An important outcome of this study was the observation that transition state theory (surface complexation models) cannot be inferred as controlling precipitation and dissolution over a wide range of saturation values if the experimental evidence was only collected over a narrow range, and for dissolution or precipitation alone.

The differential rate law has been used as the basis for a model that predicts solution composition in time and space during dissolution reactions while recognizing the influence of metastable phases, irreversible reactions, nucleation, epitaxy, and crystal ripening (Steefel and Van Capellan, 1990). The model differs from others in several ways. It recognizes that the formation of the most thermodynamically stable mineral is an irreversible reaction, but does not make any a priori decisions about the pathway for dissolution because it is completely kinetically based. Hence the sequence of precipitation of intermediary metastable phases is based on their rate of nucleation and factors that can affect nucleation (in particular, epitaxy and the interfacial tension of the solid phases considered). Simulations of granite dissolution using this comprehensive model highlighted the importance of nucleation in controlling the rate of dissolution and solution composition. Slow nucleation may be a major cause of the persistence of thermodynamically unstable mineral phases and the occurrence of solutions supersaturated with respect to the most thermodynamically stable mineral.

Transition state theory explicitly recognizes the formation of an intermediary phase or precursor $\left(A B^{*}\right)$ when reactants $A$ and $B$ combine to form a product $C$ (Sparks, 1989):

$$
A+B \rightarrow A B^{*} \rightarrow C
$$

In this case, the rate of reaction is defined by the rate constant and the concentration of the precursor rather than the reactant concentrations. Stumm and coworkers (Stumm and Wieland, 1990, and references therein) have used this approach to model the rate of dissolution of oxides in terms of protonation/hydroxylation of the surface as well as specific adsorption of ligands. They hypothesize that the rate-limiting step is the detachment of a metal center from the surface and that the precursor concentration is proportional to the surface concentration of protonated, deprotonated, or ligand bound metal ions. The effects of $\mathrm{H}^{+}$ions and ligands on dissolution rate are considered to be additive which implies that they adsorb at different sites. Such a condition is not obvious in their schematic representations of oxide surfaces (see Fig. 5). Apart from some limitations inherent in other models (Table VI), the model only applies to systems far from equilibrium in which the surface area does not change, and active sites are a small proportion of total sites and are regenerated instantly (Stumm and Wieland, 1990). Its application is also dependent on intrinsic equilibrium constants for surface reactions being available to estimate surface concentrations. 
The model has also been applied to minerals that contain constant charge surfaces as well as variable charged sites (e.g., clay minerals).

Schott et al. (1989) expanded the TST approach to allow for the rate of dissolution being a function of the formation of the precursor or activated complex at both perfect and dislocated surfaces. They found that increasing the surface area of dislocations in comparison to the perfect surface area did not increase the dissolution rate very much because the effect of increasing surface area was countered by a decrease in surface strain energy as dissolution proceeded. According to Schott (1990), dislocation densities are negligible in comparison to surface sites and hence it may be erroneous to assume that the number of active sites is related to the number of defects. In addition, it is unlikely that active sites would be instantly regenerated (as is assumed in TST models) at dislocation sites because the strain energy decreases as the hollow cores open up and dissolution would tend to become transport controlled as etch pits deepen (Schott, 1990). However, such modeling only applies for solutions far from equilibrium. Nagy and Lasaga (1992) have found that dislocation defects are important for systems near equilibrium.

Monte Carlo simulations may also be used with kinetically based models to predict the energies (i.e., measures of bonding energy) within a two-phase system and the extent of supersaturation by using statistical sampling with random numbers (Blum and Lasaga, 1987; Lasaga, 1990). The equations can also be expanded to include changes in surface energy due to defects, the effect of saturation on ordered growth and etch pit formation, and the role of dislocation defects on dissolution rates and etch pit formations. The main benefit of such simulations is their use as a form of sensitivity analysis for identifying major factors that affect surface kinetics.

\section{ALUMINUM IN ACIDIC SOILS: PRINCIPLES AND PRACTICALITIES}

The soil is an open system in which the solution composition is continuously changing in time and space in response to losses and gains by percolation into and out of a volume of soil, plant uptake and release, atmospheric deposition, evapotranspiration, application of amendments, and the removal of vegetation.

Precipitation and dissolution in a soil are the net result of all the factors discussed in the previous sections as affected by the cycling of water and soluble components and vary in time and space. In the interest of clarity, the preceding discussion has considered the effect of solution properties on dissolution and precipitation at one moment in time. In reality, however, the activities of many ions vary both spatially and temporally. For example, the activity of $\mathrm{H}_{4} \mathrm{SiO}_{4}$ 
varies seasonally due to wetting and drying and may be influenced by plant uptake (Acquaye and Tinsley, 1965). Impeded drainage in micropores in aggregates or sandy topsoils above impervious clay horizons increases contact time between minerals and the soil solution which could result in higher activities of $\mathrm{H}_{2} \mathrm{SiO}_{4}$ (Kittrick, 1969). The concentration of $\mathrm{Al}$ may increase in some soils during a dry, hot summer due to a decrease in rainfall and an increase in evapotranspiration which would both decrease soil moisture content. On the other hand, Al concentrations could decrease if the drier, hotter conditions speed up the formation of thermodynamically more stable minerals or result in coprecipitation of minerals. Inclusion decreases the solid-phase activity compared to the pure mineral solid and hence decreases Al solubility.

The importance of the effect of space and time on precipitation and dissolution has been recognized by several workers but has not received much attention partly because of the difficulty in acquiring data to test models. It has been recognized that equilibria in a soil may be very localized (Kitterick, 1969; Tardy and Nahon, 1985; Nahon, 1991; Steefel and van Capellan, 1990) and that the compositional changes in water flowing through a soil affect rates and extents of dissolution and precipitation (Kittrick, 1969; Pačes, 1978; Steefel and van Capellan, 1990).

Failing to acknowledge the three components of the framework shown in Fig. 1 and a hasty desire to develop invariant rules about the effect of solution and solid properties on dissolution and precipitation can lead to erroneous deductions of the mineral controlling Al quantities in solution. At this stage, each situation needs to be considered separately and many observations need to be made under differing conditions before paradigms can be combined into a chemical principle.

Many models have been proposed to predict the rate of dissolution and precipitation of minerals. It would appear that their application to realistic open systems is limited by the lack of appropriate data sets with which they may be tested (i.e., solution composition data collected through time and space) and the increased complication from acknowledging that a nonsteady state exists. The assumption of a steady state (i.e., $\mathrm{Al}$ flux $_{\text {in }}=\mathrm{Al}$ flux $\mathrm{xut}_{\text {out }}$ ) is a pragmatic approximation that may be too limiting for topsoils and between soil layers where the control of soluble Al changes from one phase to another (e.g., organic $\rightarrow$ mineral as water flows from organic to a clay-enriched horizon). In addition, the limitations and assumptions given in Tables II and VI need to be considered. It would appear that kinetically based models have fewer assumptions than thermodynamic approaches and are more adaptable to incorporating the factors described in the previous section and in the framework shown in Fig. 1. In particular, kinetic models can address transitions involving metastable reactants and/or products. However, further research still needs to be carried out to ascertain the overall effect of assumptions that the reactive surface area is proportional to the total 
Table VII

Suitability of Kinetic Models for Predicting Soluble Al over Different Time Periods

\begin{tabular}{|c|c|c|c|}
\hline Model & Time scale & $\begin{array}{l}\text { Level of processes } \\
\text { (model basis) }\end{array}$ & Possible uses \\
\hline $\begin{array}{l}\text { Steefel and Van Ca- } \\
\text { pellan (1990) }\end{array}$ & Years & $\begin{array}{l}\text { Macroscopic } \\
\text { (mechanistic) }\end{array}$ & $\begin{array}{l}\text { Long-term acidification ( }>5 \\
\text { years); soil formation }\end{array}$ \\
\hline $\begin{array}{l}\text { Nagy and Lasaga } \\
\text { (1992) }\end{array}$ & Days-Years & $\begin{array}{l}\text { Microscopic } \\
\text { (nonmechanistic) }\end{array}$ & $\begin{array}{l}\text { Predicting Al Toxicity to } \\
\text { plants; medium term ac- } \\
\text { idification }(<5 \text { years) }\end{array}$ \\
\hline $\begin{array}{l}\text { Stumm and Wieland } \\
(1990)\end{array}$ & Hours & $\begin{array}{l}\text { Microscopic } \\
\quad \text { (mechanistic) }\end{array}$ & $\begin{array}{l}\text { Ascertaining molecular } \\
\text { mechanisms of dissolution }\end{array}$ \\
\hline
\end{tabular}

surface area; that the density of defects is proportional to the reactive site density; and that models and mechanisms that are developed for systems far from equilibrium are applicable to systems near equilibrium. A balance between principles and practicalities is required for their application to acid soils.

The ultimate choice of a model will depend on the time scale of interest and the reason for requiring Al solubility predictions (Table VII). The kinetic models discussed in the previous section vary widely in their time scales. The mechanistic model of Steefel and Van Capellan (1990) can make predictions for open systems over many years and would be most appropriate for estimating soluble $\mathrm{Al}$ in the long term (>5-10 years) such as may be required for predicting longterm acidication rates or to ascertain how often a soil should be limed. Medium or short-term (days-years) predictions of $\mathrm{Al}$ solubility could be made with the nonmechanistic model of Nagy and Lasaga (1992) which uses macroscopic measurements of changes in free energy to predict dissolution rates. Very short-term predictions (hours-days) would be better served by the model developed by Stumm and co-workers (Stumm and Wieland, 1990). The latter model is mechanistically based and deals with molecular processes but is currently limited because measurements to test its validity can only be made at a macroscopic level.

\section{ACKNOWLEDGMENTS}

This work was conducted while on sabbatical leave at the Department of Soil Science, University of California, Berkeley, and was partially funded by a gift from the ALCOA Foundation and a grant from the Kearney Foundation of Soil Science. I thank Erich Wieland, Gary Sposito, and Andreas Gehring for helpful comments. 


\section{REFERENCES}

Acquaye, D. K., and Tinsley, J. 1965. Soluble silica in soils. In "Experimental Pedology" (E. G. Hallsworth and D. V. Crawford, eds.), pp. 126-148. Butterworth, London.

Adams, F. (1984). "Soil Acidity and Liming." Am. Agron. Soc., Madison, Wisconsin.

Amhrein, C., and Suarez, D. L. 1988. The use of a surface complexation model to describe the kinetics of ligand-promoted dissolution of anorthite. Geochim. Cosmochim. Acta 52, 27852793.

Berner, R. A. 1978. Rate control of mineral dissolution under Earth surface conditions. Am. J. Sci. 278, $1235-1252$.

Bertsch, P. M. 1989. Aqueous polynuclear aluminum species. In "The Environmental Chemistry of Aluminum" (G. Sposito, ed.), pp. 87-116. CRC Press, Boca Raton, Florida.

Binkley, D., Driscoll, C. T., Allen, H. L., Schoenberger, P., and McAvoy, D. 1989. "Acidic Deposition and Forest Soils." Springer-Verlag, New York.

Blum, A., and Lasaga, A. 1987. Monte Carlo simulations of surface reaction rate laws. In "Aquatic Surface Chemistry: Chemical Processes at the Particle-Water Interface" (W. Stumm, ed.), pp. 255-292. Wiley, New York.

Brown, G. E. 1990. Spectroscopic studies of chemisorption reaction mechanisms at oxide-water interfaces. In "Mineral-Water Interface Geochemistry" (M. F. Hochella and A. F. White, eds.), Rev. Mineral. 23, 309-364.

Cabaniss, S. E. 1987. TITRATOR: An interactive program for aquatic equilibrium calculations. Environ. Sci. Technol. 21, 209-210.

Cameron, R. C., Ritchie, G. S. P., and Robson, A. D. 1986. The relative toxicities of inorganic aluminum complexes to barley (Hordeum vulgare L.). Soil Sci. Soc. Am. J. 50, 1231-1236.

Carr, S. C., Ritchie, G. S. P., and Porter, W. M. 1991. A soil test for subsoil aluminum toxicity in the yellow earth soils of Western Australia. Aust. J. Agric. Res. 42, 875-892.

Carroll-Webb, S. A., and Walther, J. V. 1988. A surface complex reaction model for the $\mathrm{pH}$ dependence of corundum and kaolinite dissolution rates. Geochim. Cosmochim. Acta 52, 26092623.

Casey, W. H., and Bunker, B. 1990. Leaching of mineral and glass surfaces during dissolution. In "Mineral-Water Interface Geochemistry" (M. F. Hochella and A. F. White, eds.), Rev. Mineral. 23, 397-426.

Cosby, B. J., Homberger, G. M., and Galloway, J. N. 1985. Modeling the effects of acid deposition: assessment of a lumped parameter model of soil water and streamwater chemistry. Water Resour. Res. 21, 51-63.

Davis, J. A., and Hem, J. D. 1989. The surface chemistry of aluminum oxides and hydroxides. In "The Environmental Chemistry of Aluminum" (G. Sposito, ed.), pp. 185-220. CRC Press, Boca Raton, Florida.

Eary, L. E., Jenne, E. A., Vail, L. W., and Girvin, D. C. 1989. Numerical models for predicting watershed acidification. Environ. Contam. Toxicol. 18, 29-53.

Fitzpatrick, R. W., and Schwertmann, U. 1982. Al-substituted goethite. An indicator of pedogenic and other weathering environments in South Africa. Geoderma 27, 335-347.

Furrer, G., and Stumm, W. 1986. The co-ordination chemistry of weathering: I. Dissolution kinetics of $\delta-\mathrm{Al}_{2} \mathrm{O}_{3}$ and $\mathrm{BeO}$. Geochim. Cosmochim. Acta 50, 1847-1860.

Furrer, G., Sollins, P., and Westall, J. 1990. The study of soil chemistry through quasi-steady-state models: 2. Acidity of soil solution. Geochim. Cosmochim. Acta 54, 2363-2374.

Furrer, G., Zysset, M., Charlet, L., and Schindler, P. W. 1991. Mobilization and fixation of aluminum in soils. Met. Compds Environ. Life 4, 89-97.

Furrer, G., Zysset, M., and Schindler, P. W. 1993. Weathering kinetics of montmorillonite: investigations in batch and mixed-flow reactions. In "Geochemistry of Clay-Pore Fluid Interactions" 
(D. A. C. Manning. P. L. Hall, and C. R. Hughes, eds.), pp. 263-254. Chapman \& Hall, London.

Garrels, R. M., and Christ, C. L. 1965. "Solutions, Minerals and Equilibria." Harper, New York.

Helgeson, H. C. 1968. Evaluation of irreversible reactions in geochemical processes involving minerals and aqueous solutions. I. Thermodynamic relations. Geochim. Cosmochim. Acta 32, 853-877.

Hemingway, B. S. 1982. Gibbs free energies of formation for bayerite, nordstrandite, $\mathrm{Al}(\mathrm{OH})^{2+}$, and $\mathrm{Al}(\mathrm{OH})_{2}{ }^{+}$, aluminum mobility, and the formation of bauxites and laterites. Adv. Phys. Geochem. 2, 283-316.

Hemingway, B. S., and Sposito, G. 1989. Inorganic aluminum bearing solid phases. In "The Environmental Chemistry of Aluminum” (G. Sposito, ed.), pp. 55-86. CRC Press, Boca Raton, Florida.

Hering, J. G., and Stumm, W. 1990. Oxidation and reductive dissolution of minerals. In "MineralWater Interface Geochemistry" (M. F. Hochella and A. F. White, eds.), Rev. Mineral. 23, 427466.

Hochella, M. F. 1990. Atomic structure, microtopography, composition and reactivity of mineral surface. In "Mineral-Water Interface Geochemistry" (M. F. Hochella and A. F. White, eds.), Rev. Mineral. 23, 87-132.

Hsu, P. H. 1989. Aluminum oxides and oxyhydroxides. In "Minerals in the Soil Environment" (J. B. Dixon and S. B. Weed, eds.), pp. 331-378. Soil Sci. Soc. Am., Madison, Wisconsin.

Kittrick, J. A. 1969. Soil minerals in the $\mathrm{Al}_{2} \mathrm{O}_{3}-\mathrm{SiO}_{2}-\mathrm{H}_{2} \mathrm{O}$ system and a theory of their formation. Clays Clay Miner. 17, 157-167.

Lasaga, A. C. 1990. Atomic treatment of mineral-water surface reactions. In "Mineral-Water Interface Geochemistry" (M. F. Hochella and A. F. White, eds.), Rev. Mineral. 23, 17-86.

Lewis, G. N., and Randall, M. 1923. "Thermodynamics." McGraw-Hill, New York.

Lindsay, W. L. 1979. "Chemical Equilibria in Soils." Wiley, New York.

Lindsay, W. L., and Walthall, P. M. 1989. The solubility of aluminum in soils. In "The Environmental Chemistry of Aluminum" (G. Sposito, ed.), pp. 221-240. CRC Press, Boca Raton, Florida.

May, H. M., Helmke, P. A., and Jackson, M. L. 1979. Gibbsite solubility and thermodynamic properties of hydroxy-aluminum ions in aqueous solutions at $25^{\circ} \mathrm{C}$. Geochim. Cosmochim. Acta 43, 861-868.

May, H. M., Kinniburgh, D. G., Helmke, P. A., and Jackson, M. L. 1986. Aqueous dissolution, solubilities and thermodynamic stabilities of common aluminosilicate clay minerals: kaolinite and smectites. Geochim. Cosmochim. Acta 50, 1667-1677.

Mogk, D. W. 1990. Application of auger electron spectroscopy to studies of chemical weathering. Rev. Geophys. 28, 337-356.

Morse, J. W., and Casey, W. H. 1988. Ostwald processes and mineral paragenesis in sediments. Am. J. Sci. 288, 537-560.

Nagy, K. L., and Lasaga, A. C. 1992. Dissolution and precipitation kinetics of gibbsite at $80^{\circ} \mathrm{C}$ and $\mathrm{pH}$ 3: The dependence on solution saturation state. Geochim. Cosmochim. Acta 56, 3093-3111.

Nahon, D. B. 1991. Self-organization in chemical laterite weathering. Geoderma 51, 5-13.

Nielsen, A. E. 1986. Mechanisms and rate laws in electrolyte crystal growth from aqueous solution. In "Geochemical Processes of Mineral Surfaces" (J. A. Davis and K. F. Hayes, eds.), pp. 600614. Am. Chem. Soc., Washington, D.C.

Nordstrom, D. K., and May, H. M. 1989. Aqueous equilibrium data for mononuclear aluminum species. In "The Environmental Chemistry of Aluminum" (G. Sposito, ed.), pp. 29-54. CRC Press, Boca Raton, Florida.

Paces, T. 1978. Reversible control of aqueous aluminum and silica during the irreversible evolution of natural waters. Geochim. Cosmochim. Acta 42, 1487-1493.

Parks, G. A. 1990. Surface energy and adsorption at mineral/water interfaces: An introduction. In 
"Mineral-Water Interface Geochemistry" (M. F. Hochella and A. F. White, eds.), Rev. Mineral. 23, $133-176$.

Ritchie, G. S. P. 1989. The chemical behavior of aluminum, hydrogen and manganese in acid soils. In "Soil Acidity and Plant Growth" (A. D. Robson, ed.), pp. 1-60. Academic Press, San Diego.

Ritchie, G. S. P. 1994. Soluble aluminum in acidic soils: Principles and practicalities. Dev. Plant Soil Sci. (in press).

Robson, A. D., ed. 1989. "Soil Acidity and Plant Growth." Academic Press, San Diego.

Schott, J. 1990. Modeling of the dissolution of strained and unstrained multiple oxides: The surface speciation approach. In "Aquatic Chemical Kinetics" (W. Stumm, ed.), pp. 337-366. Wiley (Interscience), New York.

Schott, J., Brantley, S., Crerar, D., Guy, C., Borcsik, M., and Williams, C. 1989. Dissolution kinetics of strained calcite. Geochim. Cosmochim. Acta 53, 373-382.

Skopp, J. 1986. Analysis of time dependent chemical processes in soils. J. Environ. Qual. 38, 231266.

Sparks, D. L. 1989. "Kinetics of Soil Chemical Processes." Academic Press, San Diego.

Sposito, G. 1981. "The Thermodynamics of Soil Solutions." Oxford Univ. Press, New York.

Sposito, G. 1984. "The Surface Chemistry of Soils." Oxford Univ. Press, New York.

Sposito, G. 1986. Distinguishing adsorption from surface precipitation. In "Geochemical Processes of Mineral Surfaces" (J. A. Davis and K. F. Hayes, eds.), pp. 217-229, Am. Chem. Soc., Washington, D.C.

Sposito, G. 1989a. "The Environmental Chemistry of Aluminum." CRC Press, Boca Raton, Florida.

Sposito, G. 1989b. "The Chemistry of Soils." Oxford Univ. Press, New York.

Steefel, C. 1., and Van Capellan, P. 1990. A new kinetic approach to modelling water-rock interaction: The role of nucleation, precursors, and Ostwald ripening. Geochim. Cosmochim. Acta 54, $2657-2677$.

Stumm, W., and Wieland, E. 1990. Dissolution of oxide and silicate minerals: rates depend on surface speciation. In "Aquatic Chemical Kinetics" (W. Stumm, ed.), pp. 367-400. Wiley, New York.

Stumm, W., and Wollast, R. 1990. Coordination chemistry of weathering: Kinetics of the surfacecontrolled dissolution of oxide minerals. Rev. Geophys. 28, 53-69.

Tardy, Y. 1971. Characterization of the principal weathering types by the geochemistry of water from some European and African crystalline massifs. Chem. Geol. 7, 253-271.

Tardy, Y., and Nahon, D. 1985. Geochemistry of laterites, stability of Al-goethite, Al-hematite, and $\mathrm{Fe}^{3+}$-kaolinite in bauxites and ferricretes: an approach to the mechanism of concretion formation. Am. J. Sci. 285, 865-903.

Tsuzuki, Y. 1967. Solubility diagrams for explaining zone sequences in bauxite, kaolin and pyrophyllite-diaspore deposits. Clays Clay Miner. 24, 297-302.

Van Straten, H. A., Holtkamp, B. T. W., and de Bruyn, P. L. 1984. Precipitation from supersaturated aluminate solutions. I. Nucleation and growth of solid phases at room temperature. J. Colloid Interface Sci. 98, 342-362.

Velbel, M. A. 1986. Influence of surface area, surface characteristics, and solution composition on feldspar weathering rates. In "Geochemical Processes of Mineral Surfaces" (J. A. Davis and K. F. Hayes, eds.), pp. 615-634. Am. Chem. Soc., Washington, D.C.

Walton, A. G. 1967. "The Formation and Properties of Precipitates." Wiley, New York.

Wieland, E., and Stumm, W. 1992. Dissolution kinetics of kaolinite in acidic aqueous solutions at $25^{\circ} \mathrm{C}$. Geochim. Cosmochim. Acta 56, 3339-3355.

Wollast, R. 1967. Kinetics of the alteration of K-feldspar in buffered solutions at low temperature. Geochim. Cosmochim. Acta 31, 635-648.

Zawacki, S. J., Koutsoukos, P. B., Salimi, M. H., and Nancollas, G. H. 1986. The growth of 
calcium phosphates. In "Geochemical Processes of Mineral Surfaces" (J. A. Davis and K. F. Hayes, eds.), pp. 650-662. Am. Chem. Soc., Washington, D.C.

Zhang, J.-W., and Nancollas, G. H. 1990. Mechanisms of growth and dissolution of sparingly soluble salts. In "Mineral-Water Interface Geochemistry" (M. F. Hochella and A. F. White, eds.), Rev. Mineral. 23, 365-396. 